\title{
Diferenciais de Rendimentos entre Raças e Gêneros, nas Regiões Metropolitanas, por Níveis Ocupacionais: uma análise através do pareamento de Ñopo
}

\author{
Francisca Zilania Mariano \\ Professora - Universidade Federal do Ceará (UFC - Sobral) \\ Endereço: Rua Coronel Estanislau Frota, s/n, Bloco I - Campus Sobral - Muçambinho - Ceará/CE \\ CEP: 62010-560 - E-mail: zilania@ufc.br
}

\section{Edward Martins Costa}

Professor - Universidade Federal do Ceará (MAER/UFC)

Endereço: Av. Mister Hull, 2977 - Campus do Pici - Padre Andrade - Fortaleza - Ceará/CE

CEP: 60440-970 - Caixa Postal: 6017 - E-mail: edwardcosta@ufc.br

\section{Daniel Barboza Guimarães}

Professor - Universidade Federal do Ceará (FEAACS/UFC)

Endereço: Av. da Universidade, 2486 - Benfica - Fortaleza - Ceará/CE

CEP: 60020-180 - E-mail: barbozadan@hotmail.com

\section{Daniel Tomaz de Sousa}

Doutorando em Economia - Universidade Federal da Paraíba (PPGE/UFPB)

Endereço: Jardim Cidade Universitária - João Pessoa/PB

CEP: 58051-900 - E-mail: daniel25tomaz@gmail.com

Recebido: 17/04/2016. Aceite: 06/07/2017.

\section{Resumo}

Este artigo busca analisar o comportamento dos diferenciais de rendimentos entre gênero e raças nas regiões metropolitanas (RMs) e o Distrito Federal, considerando diferentes categorias ocupacionais. Dada a disparidade regional, optou-se por corrigir a renda através do índice de custo de vida desenvolvido por Azzoni e Almeida (2016); para captar o diferencial, os efeitos dotação e discriminação, utilizou-se o método não paramétrico de Ñopo (2008), aplicado aos dados obtidos pela PNAD (2014). Além disso, o método de Oaxaca-Blinder (1973) foi aplicado para o Brasil Metropolitano. Da comparação entre os métodos, constatou-se que Oaxaca superestima os efeitos da decomposição de rendimentos. Em relação ao diferencial, ocupacional e RM, as mulheres, assim como os indivíduos não brancos, têm piores remunerações. Com as ocupações desagregadas e por regiões, os profissionais das ciências e das artes são aqueles que têm as maiores diferenças salariais nas RMs por gênero; por raça, as maiores diferenças são encontradas para o grupo de dirigentes e profissionais das ciências e das artes.

\section{Palavras-Chave}

Diferenciais de rendimentos. Categorias ocupacionais. Discriminação.

- Os autores agradecem ao professor/pesquisador da Esalq-USP Alexandre Nunes de Almeida pela disponibilização da base de dados do índice de custo de vida (ICV) das regiões metropolitanas. 


\begin{abstract}
This paper analyzes the behavior of income differentials between gender and race in the metropolitan regions (MRs) and the Federal District, considering four levels of occupation. Given the regional disparity, it was decided to correct the income by the cost of life index developed by Azzoni and Almeida (2016). To capture the differential effects allocation and discrimination, we used the nonparametric method Nopo (2008) applied to the data obtained from the National Household Survey (2014). Furthermore, the method of Oaxaca-Blinder (1973) was applied to the Metropolitan Brazil. Comparing the methods, it can be seen that Oaxaca overestimates the effects of income decomposition. Regarding the differential in each RM and occupational level, women as well as non-white individuals have worse pay. With the disaggregated occupations and by regions, the professionals of the sciences and the arts are the one that has the greatest salary differences in RMs by gender, and by race, the biggest differences are found for the group of leaders and professionals of the sciences.
\end{abstract}

\title{
Keywords
}

Income differentials. Occupational categories. Discrimination.

\section{JEL Classification}

J71. C01.

\section{Introdução}

Nos últimos anos, a partir de pesquisas desenvolvidas com base na RAIS, CAGED, PME e PNAD, o mercado de trabalho brasileiro apresentou progressos significativos tais como a redução da taxa de desemprego, ${ }^{1}$ que passou de $13 \%$ para 5,4\%, no período de 2003 a 2013. Além disso, de acordo com Saboia (2014), podem ser apontadas as seguintes mudanças: o crescimento do número de pessoas ocupadas, o aumento da escolaridade da mão de obra, a elevação da remuneração do trabalho, a queda da desigualdade de rendimentos e a redução da informalidade.

De acordo com a Organização Internacional do Trabalho (2012), durante o período de 2003 a 2010, houve um crescimento de cerca de $53,6 \%$ de empregos formais, sendo criados 15,3 milhões de novos postos de trabalho nesse período. Como resultado desse cenário, existe uma expectativa de aumento do aperfeiçoamento por parte dos agentes econômicos (empresas, trabalhadores e o governo), tanto de técnicas de administração, por parte dos gestores/empresários, quanto de aperfeiçoamento através da educação técnica/ou não, por parte dos trabalhadores.

1 Ver Tabela 1, na seção 2. 
Embora a desigualdade de renda tenha diminuído nos últimos anos, o nível de concentração de renda ainda prevalece elevado no Brasil. E este configura-se como um dos principais problemas enfrentados pelo país. Pode-se afirmar que além do problema econômico, a desigualdade brasileira proporciona uma má distribuição de oportunidades de inclusão econômica e social, caracterizando uma baixa mobilidade social (Guimarães 2013).

Existe uma significante variedade de abordagens na literatura sobre os determinantes da disparidade de renda, nos quais, dentre os fatores levantados para justificar o elevado grau de concentração de renda estão: sexo, raça, região de moradia, idade e escolaridade. Muitos autores concebem que os benefícios do investimento em capital humano, especialmente através da educação, impulsionam o desenvolvimento a outros estágios, afirmando que a educação, além de aumentar a produtividade, promove uma maior igualdade à medida que é bem distribuído assim para a mobilidade social (Wang Yan 2001; Oliveira 2004; Pessoa et al. 2007).

Com as mudanças ocorridas do mercado de trabalho, principalmente nas últimas décadas, houve aumento da participação de trabalhadores do sexo feminino, que era de aproximadamente de 57\% em 1992 para 64\% em 2009 (OIT 2012). Contudo, ainda existem indícios de discriminação salarial em favor dos trabalhadores do sexo masculino (Cavaliere 1998; Cambota 2005; Giuberti; Menezes-Filho 2005; Souza; Camara 2005; Carvalho; Neri; Silva 2006; Matos; Machado 2006; Cacciamali; Tatei; Rosalino 2008; Freisleben; Bezerra 2012; Menezes 2013; Guimarães 2013; Fiuza; Moura 2015; Gomes; Souza 2016). Esses estudos evidenciaram, com maiores ou menores efeitos, que pessoas com características semelhantes possuem diferentes retornos salariais. Como consequência, existe um hiato salarial entre homens e mulheres, brancos e não brancos e residentes de regiões mais e menos desenvolvidas.

Em alguns casos, atributos adquiridos como o nível de educação e experiência parecem ter menor relevância que o gênero ou a raça de um trabalhador. Segundo dados da PNAD 2011, mulheres e homens com 10 anos ou mais de idade apresentaram, em média, 7,5 e 7,1 anos de estudo, respectivamente; no entanto, o rendimento médio mensal dos indivíduos do sexo masculino ( $\mathrm{R} \$ 1129)$ ainda é muito maior que o das mulheres ( $\mathrm{R} \$ 650)$. 
Outra abordagem que também busca explicar os diferenciais de salários e que diverge da teoria de capital humano é a teoria da segmentação, a qual busca focar não o nível educacional, mas sim o posto de trabalho, local onde a renda é gerada. Segundo Araújo et al. (2011), se a Teoria do Capital Humano sugere que níveis mais altos de educação correspondem a níveis mais altos de renda, por outro lado, a Teoria da Segmentação admite que se as ocupações forem classificadas segundo sua natureza, o papel da educação na determinação do rendimento tende a diminuir, sobretudo naqueles segmentos caracterizados por maior rotatividade da mão de obra, salários relativamente baixos, piores condições de trabalho, baixa produtividade do trabalho e estagnação tecnológica.

Com isso, as diferenças salariais observadas entre pessoas de distintas etnias e gênero podem apresentar comportamentos diferenciados, pois dependendo do setor de trabalho e atividade desenvolvida, a discriminação pode ter impacto e intensidade diferentes. Cada categoria ocupacional exige níveis diferentes de capital humano, partindo desse ponto faz-se necessário a investigação desagregando as ocupações (Menezes 2013).

O mercado de trabalho metropolitano é diferenciado entre as regiões. Isso se deve pelo forte dinamismo presente em cada mercado de trabalho local. Para Saboia (2014), nas regiões mais desenvolvidas, tem-se mercados de trabalho mais consolidados que, por sua vez, podem enfrentar melhor as mudanças na economia. Por outro lado, nas regiões menos desenvolvidas, o mercado de trabalho é mais vulnerável a essas mudanças. Outro fator importante que torna diferenciado o mercado de trabalho entre as regiões é o custo de vida presente nesses locais. Almeida e Azzoni (2016), ao analisar o comportamento dos índices relativos de custo de vida nas regiões metropolitanas, verificaram que o custo de vida tem efeito direto sobre as desigualdades de renda per capitas em cada região, o que impacta diretamente o mercado de trabalho nessas localidades.

Diante do exposto, este trabalho utiliza dados da PNAD 2014 e duas metodologias econométricas, decomposição de Oaxaca-Blinder (1973) e a decomposição não paramétrica de Nopo (2008), para mensurar o comportamento do diferencial salarial, tanto por gênero quanto por raça, nas Regióes Metropolitanas brasileiras (RMs). Na literatura sobre discriminação salarial, o método mais utilizado é o de Oaxaca-Blinder (1973), entretanto, esse procedimento tende a analisar grupos sem características comparáveis, o que pode causar uma superestimação do hiato total da discriminação, 
diferentemente do método de Ñopo que, ao comparar grupos dentro de um suporte comum, obtém resultados mais precisos da diferença salarial. Dessa forma, a contribuição deste trabalho para a literatura apresenta-se, principalmente, por mensurar o efeito da discriminação, através de uma técnica que permite decompor a diferença salarial onde exista um suporte comum das distribuições de características dos grupos analisados, verificando somente indivíduos com os mesmos atributos. Além disso, este estudo realiza a desagregação por ocupações nas regiões metropolitanas, bem como a incorporação do índice de custo de vida (ICV) dessas regiões.

A opção por realizar esta análise, considerando as RMs, deve-se ao fato de que segundo os estudos do Observatório das Metrópoles, ${ }^{2}$ Grandes Espaços Urbanos Brasileiros Metropolitanos (GEUBs) concentraram 52,5\% e 47,4\% do PIB brasileiro em 2005 e 2009, respectivamente. Ademais, as regiões consideradas metropolitanas concentram cerca de $62 \%$ da capacidade tecnológica ${ }^{3}$ do país, fator fundamental para o desenvolvimento e crescimento econômico, além de representarem $36,3 \%$ da população brasileira. ${ }^{4} \mathrm{Em}$ virtude das diferenças salariais entre as ocupações e/ou classes de emprego verificadas nos estudos de Menezes (2013); ${ }^{5}$ Guimarães (2013); ${ }^{6}$ Gomes; Souza (2016), ${ }^{7}$ voltados a analisar a presença de discriminação no mercado de trabalho no Brasil, este artigo também busca verificar possíveis diferenças salariais entre homens e mulheres e brancos a não brancos, em quatro níveis ocupacionais (Dirigentes, profissionais das ciências das artes, serviços e técnicos).

Além desta introdução, este trabalho está dividido em mais quatro seções. A próxima faz uma breve revisão de literatura sobre o tema em análise e alguns índices recentes do mercado de trabalho metropolitano. Em seguida, são enumeradas a base de dados adotada e a metodologia para

2 Pesquisa disponível em http://www.observatoriodasmetropoles.ufrj.br/relat0092009b.pdf.

3 A capacidade tecnológica é medida pelo número de patentes, artigos científicos, população com mais de 12 anos de estudos e pelo valor bruto da transformação industrial (VTI).

4 Esse percentual da população das metrópoles leva em consideração características especiais consideradas pelo Observatório das Metrópoles. Já levando em consideração as regiões metropolitanas oficiais esse percentual se eleva para $44,7 \%$.

5 Realizou uma separação em sete níveis ocupacionais (profissionais administradores e gerentes, trabalhadores não manuais de rotina, pequenos proprietários, trabalhadores manuais qualificados técnicos e supervisores, trabalhadores manuais não qualificados, empregadores e proprietários rurais, trabalhadores manuais não qualificados do setor rural) a partir do esquema EGP, para analisar as lacunas de rendimentos entre gênero, raça e região de habitação (Nordeste ou em outra região).

6 Mensurou diferenciais de rendimento entre homens e mulheres por setor ocupacional (dirigentes, serviços, técnicos e todas as ocupações) e por níveis regionais (Brasil, Nordeste, Sul e Sudeste).

7 Verificaram as diferenças salariais por gênero na região nordeste do Brasil, segundo as classes de emprego (primeiro emprego, reemprego e remanescentes) e setores econômicos. 
decompor o diferencial salarial. Em seguida a discussão dos resultados e considerações finais.

\section{Mercado de Trabalho e Estudos Empíricos}

\subsection{Mercado de Trabalho: Evidências para as Regiões Metropolitanas}

O estudo do mercado de trabalho é peculiar e, por vezes, dificultoso. De acordo com Ramos (2007), a grande questão envolvida nas análises está em definir o trabalho como uma mercadoria que é transacionada, tendo dessa forma preço definido pelos mecanismos de oferta e demanda. Contudo, o processo de definição de seu preço não é simples. As características dos indivíduos são de extrema importância para que os postos de trabalho tenham remunerações adequadas de acordo com o nível de preparo de cada um.

No entanto, Rocha e Magalhães (2013) afirmam que apenas uma parcela do salário dos trabalhadores é explicada por suas características, e que a outra parcela, denominada de parte residual do salário, é atribuída a fatores associados às regiões. Esse resíduo salarial, portanto, pode ser atribuído a fatores locais associados às regiões metropolitanas e pode ser utilizado como um indicador da qualidade de vida local. Os autores verificam que há diferenças regionais nas remunerações no mercado de trabalho, com relação à raça e ao sexo dos trabalhadores.

Almeida e Azzoni (2016) verificam que a desigualdade regional das rendas per capita deflacionadas é sempre menor do que a calculada, sem levar em conta as diferenças em níveis de custo de vida. Esse é um bom exemplo da utilidade dos indicadores de níveis de custo de vida regionais em análises de diferenciais das condições sociais entre distintas áreas, já que ignorar essa dimensão levaria a superestimar a extensão da desigualdade.

No tocante ao comportamento da taxa de desemprego, Camargo (2014) verifica que o desempenho do mercado de trabalho brasileiro pode ser dividido em três períodos: a década de 1980, que apresentou taxas de desemprego bastante baixas, entre 4,5\% e 5\% da força de trabalho; a década de 1990, período em que esta taxa aumentou rapidamente, chegando a 
13\% no início dos anos 2000; e durante esse ano, fase marcada por uma redução sistemática do desemprego, chegando a atingir o patamar de 5,5\% da força de trabalho, retornando ao comportamento da década de 1980.

Curi e Menezes-Filho (2004), analisando a evolução do mercado de trabalho metropolitano para o período 1990-2000, demonstraram que houve redução da taxa de emprego formal em todos os níveis de educação, em especial para níveis educacionais elevados. Simetricamente, a proporção de pessoas em empregos informais (sem carteira) aumentou, sendo mais evidente para trabalhadores com mais de 11 anos de estudo.

Segundo as considerações de Ramos (2007), porém, a participação no mercado de trabalho apresentou tendências diferentes na desagregação por gênero. A participação masculina teve um decréscimo de aproximadamente 4 p.p. no período 1992-2005 já a feminina teve um aumento de 7 p.p. no mesmo período. Verificando os diferenciais salariais devido ao gênero, este reduziu de $80,5 \%$ para $46,9 \%$. Essa diminuição de fatores puramente discriminatórios tem efeitos benignos para a promoção de igualdade dentro da economia.

Em estudo mais recente, Saboia (2014) utilizou nove variáveis para mensurar a qualidade do mercado de trabalho nas regiões metropolitanas compreendidas pela PME no período 2010-2013. O autor verificou que o mercado de trabalho tendia a apresentar resultados mais favoráveis em 2013, quando comparado aos anos anteriores. Uma vez que a taxa de desemprego e o desemprego de longa duração apresentaram redução, a subocupação apresentou níveis muito baixos (em 2013 menos de 2\% das pessoas ocupadas trabalhavam menos de 40 horas semanais), a sub-remuneração permanecia praticamente no mesmo patamar dos anos anteriores, enquanto a remuneração média, em relação ao percentual de empregados com carteira assinada e a escolaridade dos trabalhadores, apresentou clara evolução. Conforme os resultados apresentados pelo autor, apenas o percentual de chefes de família entre as pessoas desempregadas apresentou uma piora, flutuando entre $24 \%$ e $28 \%$ no período analisado. Sobre esse assunto, Menezes-Filho, Cabanas e Komatsu (2014) realizaram um levantamento das últimas tendências do mercado de trabalho nas regióes metropolitanas brasileiras. A Tabela 1, apresentada a seguir, sintetiza algumas das informações destacadas pelos pesquisadores. 
Percebe-se que o desemprego nas RMs apresentou queda, de acordo com as informações da Tabela 1, passando de 13\% em 2003, para 5,4\% em 2013. De forma paralela à redução da taxa de desemprego, o mercado de trabalho apresentou fortes ganhos salariais a partir de 2004; de acordo com Barbosa-Filho (2014), a partir de 2005, os trabalhadores obtiveram ganhos reais $(1,5 \%)$. Desde então, o salário real tem crescido em ritmo elevado, tendo apresentado crescimento mesmo em 2009, ano em que a crise iniciada em 2008 atinge de forma mais forte a economia nacional. O autor ainda afirma que o ano de 2012 foi o que apresentou o maior crescimento do rendimento real (expansão de 4,1\%), mas que em 2013 houve desaceleração (aumento de 1,9\%). De acordo com o autor, essa redução no crescimento do rendimento real é explicada por uma menor elevação do rendimento nominal (ainda elevada) acompanhada por aumento da taxa de inflação.

Tabela 1 - Tendências do mercado de trabalho nas Regiões Metropolitanas, 2003,2008 e 2013

\begin{tabular}{lccc}
\hline & 2003 & 2008 & 2013 \\
\hline Taxa de Desemprego (\%) & 13 & 7,7 & 5,4 \\
Empregados com Carteira assinada (\%) & 53 & 58 & 66 \\
PIA $^{8}$ (em milhões) & 37 & 40 & 43 \\
PEA (em milhões) & 22 & 23 & 25 \\
Proporção (\%) da População em Idade Ativa na População total & 84 & 87 & 89 \\
Total de Empregados (Milhões) & 14 & 16 & 18 \\
Empregados com Carteira Assinada (Milhões) & 7 & 9 & 12 \\
\hline
\end{tabular}

Fonte: Menezes-Filho, Cabanas e Komatsu (2014) a partir de dados da PME/IBGE e PNAD/IBGE.

Não obstante, Barbosa-Filho (2014) aponta ainda uma redução na taxa de informalidade, em que esta caiu de 34,6\% em dezembro de 2004, para $22,7 \%$ em dezembro de 2012, sendo que, nesse ano, tal taxa apresentou estabilidade. No entanto, tal trajetória decrescente, que parecia ter se interrompido ao longo de 2012, volta a crescer em 2013, quando a taxa de informalidade atinge $20,3 \%$ em dezembro, configurando, portanto, um novo período de aceleração na redução da informalidade, que fecha 2013 em $21 \%$. Já os empregos formais (com carteira assinada) tiveram tendência ascendente, saindo de 53\% em 2003, para 66\% em 2013. Além disso, em

8 Apesar da mudança a partir de 2011, do conceito de População em Idade Ativa, os autores usaram o conceito antigo, para ser mais fácil a comparação. A partir de 2011, o IBGE passou a adotar a População em Idade Ativa as pessoas com 15 ou mais anos de idade, não mais a partir de 10 anos de idade ou mais. As pessoas entre 10 e 14 anos têm pouca representatividade na força de trabalho do Brasil. 
2013, a PIA representou $89 \%$ da população total das RMs, e os trabalhadores com carteira assinada, em relação ao total de empregados, representavam 50\% em 2003, 56,25\% em 2008 e 66,67\% em 2013.

Diante disso, pode-se observar que o mercado de trabalho brasileiro apresentou melhoras significativas nos últimos anos, uma vez que os dados apontam ter havido redução das taxas de desemprego e de informalidade e elevação da renda real. Barbosa-Filho (2014) chega, inclusive, a afirmar que o aumento do pessoal ocupado, acompanhado pela forte elevação de renda ocorrida em 2011 e 2012, indica que o mercado de trabalho, pelo menos nas regiões metropolitanas pesquisadas pela PME, encontra-se operando em níveis bem próximos do pleno-emprego.

No entanto, Barbosa-Filho (2014) verifica uma suave desaceleração do mercado de trabalho brasileiro que, apesar de estar gerando menos vagas do que antes, continua aquecido. Com isso, a taxa de desemprego deve continuar em patamares baixos, mas com tímida elevação nos próximos meses. De acordo com o autor, o menor crescimento populacional e dos rendimentos reais certamente são fatores importantes na compreensão desse fenômeno.

Além disso, Saboia (2014), ao analisar os resultados das distintas regiões metropolitanas cobertas pela PME, observou comportamentos diferenciados. Enquanto as mais desenvolvidas e formalizadas, São Paulo (principalmente), Rio de Janeiro, Belo Horizonte e Porto Alegre, parecem enfrentar melhor o pouco crescimento econômico, as menos desenvolvidas e mais informais, Salvador e Recife, mostram-se mais frágeis. Tais resultados são, mais uma vez, a confirmação dos grandes diferenciais regionais existentes no país.

\subsection{Diferenciais de Rendimentos: Evidências Empíricas}

Uma das primeiras tentativas de se formular uma medida que captasse discriminação no mercado de trabalho foi elaborada por Oaxaca (1973), o qual desenvolveu uma medida para decompor as diferenças salariais entre homens e mulheres nos Estados Unidos. Os resultados indicaram que o diferencial de salários entre homens e mulheres era bastante significativo, e que uma substancial proporção desses diferenciais era atribuída aos efeitos 
da discriminação. Em seguida, Blinder (1973) desenvolveu uma metodologia para quantificar a discriminação no mercado de trabalho americano por meio de um sistema de equações simultâneas. A partir da estimação do sistema, o autor conclui que o diferencial de salário entre homens e mulheres é atribuído em cerca de $2 / 3$ à discriminação absoluta no mercado de trabalho.

A partir da metodologia desenvolvida por Oaxaca (1973) e Blinder (1973), posteriormente denominada de decomposição de Oaxaca-Blinder (1973), as estimavas da presença de discriminação no mercado de trabalho tornaram-se rotina, uma vez que tal metodologia permite realizar uma decomposição das diferenças salariais em dois efeitos: discriminação (não explicada) e diferenças entre as características individuais (explicada).

Dentre os trabalhos que utilizam essa metodologia, El-Haddad (2009) examina a evolução da qualidade dos salários e do emprego para homens e mulheres nos setores público e privado do Egito entre 1998 e 2006. A decomposição de Oaxaca mostra que uma parte significativa das diferenças salariais mensais entre homens e mulheres é devida à discriminação. Em 2006, as mulheres receberam salários 37\% mais baixos, em média, devido a uma injustificada discriminação.

Mysíková (2012), por sua vez, utiliza o modelo de seleção de Heckman e a decomposição de Oaxaca-Blinder para analisar as diferenças salariais entre homens e mulheres na República Tcheca, Hungria, Polônia e Eslováquia. Os resultados mostram que uma parte relativamente pequena, mas positiva, da diferença salarial observada entre homens e mulheres pode ser explicada pela variável gênero. Portanto, esse resultado não poderia ser interpretado como uma constatação de um elevado grau de discriminação salarial entre homens e mulheres, uma vez que outros fatores, não utilizados, estariam contribuindo para uma significante parcela do diferencial salarial.

No Brasil, alguns estudos buscam mensurar a magnitude dessa discriminação. Usando um modelo minceriano adaptado, Cavalieri e Fernandes (1998) constatam que em média tanto os rendimentos dos homens são superiores aos das mulheres assim como os de pessoas não brancas são inferiores aos de pessoas de cor branca. Esse resultado foi encontrado tanto para as regiões metropolitanas como um todo, e também para a análise em separado destas regiões. O maior diferencial foi encontrado na região metropolitana de Salvador, enquanto menor diferencial, em São Paulo. 
Utilizando dados da PNAD de 2003, Carvalho, Neri e Silva (2005) estimam a equação de salários (Mincer 1974) com a correção do viés de seleção das informações (Heckman 1979) e, após isso, utilizam a decomposição de Oaxaca (1973) para decompor o diferencial de salários, por cor e sexo, dos trabalhadores brasileiros. Os resultados apontam que o fator discriminação explica $97 \%$ do diferencial de salários entre homens de cor branca e as mulheres de cor preta ou parda.

Cambota (2005) demonstrou, a partir dos dados da PNAD 2002, que existe discriminação nas regiões Nordeste e Sudeste do Brasil, sendo esta maior para as mulheres do que para negros, e mais presente em intervalos mais altos, dificultando o acesso a cargo de chefias apenas por um fator discriminatório. A autora salienta que parte desse diferencial pode ser atribuída a outros fatores não discriminatórios e que não foram considerados na pesquisa, e indica que as políticas públicas devem ser mais ativas tanto no que concerne à diminuição da discriminação por gênero quanto por raça, além da importância das diferenças regionais.

Guimarães (2013) realizou uma análise dos rendimentos por setor (dirigentes, serviços, técnicos e todas as ocupações) e ainda por níveis regionais (Brasil, Nordeste, Sul e Sudeste); seus resultados apontaram que independentemente do setor ou região, as mulheres ganham em média menos que os homens, controlando por setor de ocupação e região a diferença salarial por sexo, que é de no mínimo 36,31\% na média. A diferença é menor para o grupo de dirigentes; pessoas pertencentes ao grupo de técnicos e região Nordeste apresentam os maiores diferenciais por gênero.

Souza et al. (2015) realizou a estimação de equações mincerianas juntamente com a decomposição de Oaxaca-Blinder (1973) para mensurar as diferenças salariais e o impacto da discriminação por gênero e cor no mercado de trabalho brasileiro, a partir dos microdados da PNAD de 2013. Os resultados mostram que o gênero e a cor, em conjunto, potencializam as diferenças salariais no Brasil. As características estudadas dos indivíduos explicam um quarto dessas diferenças, e a discriminação de gênero e cor os três quartos restantes.

Gomes e Souza (2016) analisam as diferenças salariais por gênero na região nordeste do Brasil, segundo as classes de emprego e setores econômicos, com base nos dados da Relação Anual de Informações Sociais, em 2013. Dos resultados, observaram que as dotações (produtivas e não produtivas) 
masculinas são contratadas com salários superiores às femininas. Através da decomposição de Oaxaca-Blinder, verificaram discriminação de rendimentos contra as mulheres na região, mesmo no setor de serviços em que a absorção ocupacional das mulheres é maior. Na agricultura e indústria, as mulheres são discriminadas duplamente, tanto na inserção ocupacional quanto nos rendimentos, agravada no setor industrial; o setor de comércio apresentou as menores diferenças e discriminação de rendimentos contra as mulheres. A maior discriminação de gênero na região está na classe daquelas que já estão inseridas no mercado de trabalho.

\section{Metodologia}

\subsection{Base de Dados}

O presente trabalho utiliza dados da Pesquisa Nacional por Amostra de Domicílio (PNAD), a qual é fornecida com frequência anual, exceto nos anos censitários, pelo Instituto Brasileiro de Geografia e Estatística (IBGE). A PNAD utilizada será a de $2014 .{ }^{9}$ As variáveis selecionadas foram escolhidas baseadas na teoria do capital humano e com base na literatura sobre os diferenciais de rendimentos no mercado de trabalho, assegurando, portanto, os seus níveis de importância quanto à explicação dos retornos salariais. O quadro abaixo sintetiza as variáveis adotadas.

É importante salientar que devido a algumas restrições da pesquisa, diversos filtros de seleção foram utilizados para se chegar a uma amostra mais homogênea possível: foram selecionados indivíduos pertencentes à faixa etária dos 16 aos 65 anos de idade, onde os extremos, inferior e superior, foram definidos levando em conta a real possibilidade de estes indivíduos estarem no mercado de trabalho das regiões metropolitanas, considerando ser a PIA composta de pessoas com 16 ou mais anos de idade e que após 65 anos boa parte da força de trabalho pode já estar aposentada.

9 Este trabalho utilizou a PNAD 2014 por ser ano mais recente de sua publicação. Vale ressaltar que, como o objetivo do trabalho consiste na aplicação de uma nova metodologia aos diferenciais de rendimento, a fim de verificar se os resultados presentes na literatura estão superestimados, a análise de um cross-section apresenta-se adequada. 


\section{Quadro 1 - Descrição das variáveis}

\begin{tabular}{|c|c|}
\hline Variáveis & Descrição \\
\hline Lnw & $\begin{array}{l}\text { Logaritmo natural do rendimento do trabalho principal corrigido pelo custo de vida das regiões } \\
\text { metropolitanas }\end{array}$ \\
\hline \multicolumn{2}{|l|}{ Pessoais } \\
\hline Educ & Anos de Educação. \\
\hline Exp & Experiência ${ }^{10}$ do Indivíduo. \\
\hline Exp2 & Experiência ao quadrado. \\
\hline Sexo & 1 se o indivíduo for do sexo masculino, 0 caso contrário. \\
\hline Raça & $\begin{array}{l}\text { Oaxaca: } 1 \text { se o indivíduo for branco, } 0 \text { se não branco. } \\
\text { Ñopo: } 1 \text { se o indivíduo for não branco, } 0 \text { se branco. }\end{array}$ \\
\hline Casado & 1 se indivíduos é casado; 0 caso contrário \\
\hline Nfamília & Número de componentes da família \\
\hline \multicolumn{2}{|c|}{ Mercado de trabalho } \\
\hline Sind & 1 se indivíduo é filiado a algum sindicato; 0 caso contrário \\
\hline Formal & 1 se indivíduo pertence ao setor formal; 0 caso contrário. \\
\hline Horas & Horas de trabalho por semana \\
\hline \multicolumn{2}{|l|}{ Atividades } \\
\hline Indústria & 1 se pertence a atividades industriais; 0 caso contrário. \\
\hline Comserv & 1 se pertence a atividades de Comércio e Serviços; 0 caso contrário. \\
\hline Social & 1 se pertence a atividades Educação Saúde social; 0 caso contrário. \\
\hline Outras & 1 se pertence a Outras Atividades; 0 caso contrário. \\
\hline \multicolumn{2}{|l|}{ Ocupações } \\
\hline Dirig & 1 se pertence a ocupações dos dirigentes; 0 caso contrário \\
\hline Ciênciasartes & 1 se pertence a ocupações dos profissionais das ciências e das artes; 0 caso contrário \\
\hline Serv & 1 se pertence a ocupações dos serviços; 0 caso contrário \\
\hline Técnicos & 1 se pertence a ocupações dos técnicos; 0 caso contrário \\
\hline \multicolumn{2}{|l|}{ Regionais } \\
\hline RMB & 1 se pertence a região metropolitana de Belém; 0 caso contrário. \\
\hline RMF & 1 se pertence a região metropolitana de Fortaleza; 0 caso contrário. \\
\hline RMR & 1 se pertence a região metropolitana de Recife; 0 caso contrário. \\
\hline RMS & 1 se pertence a região metropolitana de Salvador; 0 caso contrário. \\
\hline RMBH & 1 se pertence a região metropolitana de Belo Horizonte; 0 caso contrário. \\
\hline RMRJ & 1 se pertence a região metropolitana do Rio de Janeiro; 0 caso contrário. \\
\hline RMSP & 1 se pertence a região metropolitana de São Paulo; 0 caso contrário. \\
\hline $\mathrm{RMC}$ & 1 se pertence a região metropolitana de Curitiba; 0 caso contrário. \\
\hline RMPA & 1 se pertence a região metropolitana de Porto Alegre; 0 caso contrário. \\
\hline RMDF & 1 se pertence a região metropolitana do Distrito Federal; 0 caso contrário. \\
\hline
\end{tabular}

Nota: Optou-se por seguir a mesma classificação da variável raça utilizadas nos métodos de Oaxaca e de Nopo.

Fonte: Dados da Pesquisa. Elaboração Própria.

${ }^{10}$ Experiência=idade-anos de educação-6, em que se assume que o indivíduo ingressa no mercado de trabalho após a fase escolar; 6 é a idade em que a pessoa ingressa na escola no Brasil. A anexação dessa variável enfatiza a importância do treinamento no mercado de trabalho. 
Devido à existência da grande disparidade regional nos níveis de renda, bem-estar, assim como nos níveis de custo de vida entre regiões e cidades (Azzoni et al. 2003), este trabalho optou por corrigir a renda dos indivíduos através do índice de custo de vida desenvolvido por Azzoni e Almeida (2016) para as regiões metropolitanas. ${ }^{11}$ O autor estimou níveis de custo de vida aplicando o método de Country Product Dummy (CPD) aos dados das pesquisas de orçamentos familiares, e constatou que os maiores custos de vida estão presentes no Distrito Federal, São Paulo e Rio de Janeiro.

A escolha dessas ocupações, para este estudo, foi feita a partir da variável disponibilizada pela PNAD, na qual se verificam os grupamentos de ocupações do trabalho principal. ${ }^{12}$ Optou-se por considerar apenas os grupos dos Dirigentes, Profissionais das Ciências e das Artes, Técnicos e Serviços, composto pelos trabalhadores dos serviços, vendedores, prestadores de serviço do comércio trabalhadores na produção de bens e serviços e de reparação e manutenção, os quais representam $86 \%$ da participação percentual das ocupações. Vale ressaltar que foram aplicados os seguintes filtros: 1) exclusão dos militares, por seus salários não serem determinados pelas forças de mercado; 2) Exclusão dos trabalhadores agrícolas, por não ser uma parcela significativa dos trabalhadores das regióes metropolitanas e 3) exclusão das ocupações mal definidas.

Os indivíduos que não residiam em regiões metropolitanas também foram excluídos, assim como aqueles que não declararam os rendimentos. As regiões metropolitanas consideradas pela PNAD são as seguintes: Belém, Fortaleza, Recife, Salvador, Belo Horizonte, Rio de Janeiro, São Paulo, Curitiba e Porto Alegre, além do Distrito Federal, como explicitadas no Quadro 01.

11 Tabela Al em anexo.

12 Dirigentes em geral, profissionais das ciências e das artes, técnicos de nível médio, trabalhadores dos serviços, vendedores e prestadores de serviço do comércio, trabalhadores agrícolas, trabalhadores na produção de bens e serviços e de reparação e manutenção, membros das forças armadas e auxiliares e ocupações mal definidas. 


\subsection{Modelagem Econométrica}

\subsubsection{Modelo Minceriano e Decomposição de Oaxaca e Blinder (1973)}

Os diferenciais salariais podem ser explicados por diversos fatores. Oaxaca (1973) encontrou evidências de que parte do diferencial relativo ao gênero é devido à discriminação presente no mercado de trabalho. Blinder (1973) também mostra que o diferencial salarial entre brancos e negros, homens e mulheres é devido à presença de discriminação. A presença de discriminação é constatada quando um grupo com elementos produtivos iguais recebe menos que outro apenas por características que não têm interferência na produtividade, como por exemplo, sexo, cor ou origem. Para análises de discriminação por gênero e cor, usa-se o processo de decomposição de Oaxaca e Blinder (1973). A primeira parte do procedimento é composta pela estimação de equações mincerianas desenvolvida por Mincer (1974), em que é possível fazer inferências sobre o retorno de cada variável explicativa sobre o logaritmo natural do salário $(\ln \mathrm{W})$, o qual é explicado por um vetor de variáveis $(X i)$ de controle e de discriminação. As variáveis de controle são: educação, experiência, já as de discriminação são gênero e cor.

$$
\ln \mathrm{W}=\beta_{i} X i+u_{i}
$$

Para calcular o diferencial, por meio da decomposição de Oaxaca e Blinder (1973), ${ }^{13}$ são estimadas equações de salários para ambos os grupos em análise.

$$
\begin{aligned}
& \ln \mathrm{W}_{A}=\beta_{A} X_{A}^{\prime}+u_{A} \\
& \ln \mathrm{W}_{B}=\beta_{B} X_{B}^{\prime}+u_{B}
\end{aligned}
$$

Onde $\mathrm{W}, X$ e $u$ são o rendimento, conjunto de variáveis explicativas e o termo de erro aleatório, respectivamente. Os subscritos A e B representam os dois grupos em comparação. Decompondo o diferencial (decomposição two-fold, ou em dois termos), obtém-se a seguinte equação:

$$
\ln \bar{W}_{A}-\ln \bar{W}_{B}=\underbrace{\left(\bar{X}_{A}-\bar{X}_{B}\right) \hat{\beta}_{B}}_{\text {Efeito Dotação }}+\underbrace{\bar{X}_{A}\left(\hat{\beta}_{A}-\hat{\beta}_{B}\right)}_{\text {Efeito Discriminação }}
$$

\footnotetext{
${ }^{13}$ Para mais detalhes sobre o processo de decomposição ver Fortin, N.M., T. Lemieux, S. Firpo (2011) e Jann (2008).
} 
O termo $\left(\bar{X}_{A}-\bar{X}_{B}\right) \hat{\beta}_{B}$ é a parte do diferencial atribuída às características produtivas dos indivíduos, denominado neste trabalho de "efeito dotação". Aqui o coeficiente de B é mantido fixo, e avalia-se o diferencial em função das características observadas. Enquanto $\bar{X}_{A}\left(\hat{\beta}_{A}-\hat{\beta}_{B}\right)$ é a parte do diferencial que é atribuída à diferença nos retornos das características individuais, mas que não são produtivas, aqui denominado de "efeito discriminação". Esse procedimento será realizado para o grupo que pode haver discriminação, brancos e não brancos e mulheres e homens. Sendo os subscritos A, o grupo de mulheres $(m)$ e não brancos $(n b)$ e B, o grupo de homens $(h)$ e brancos $(b)$. Portanto, serão obtidas as seguintes decomposições:

$$
\begin{aligned}
& \ln \bar{W}_{m}-\ln \bar{W}_{h}=\underbrace{\left(\bar{X}_{m}-\bar{X}_{h}\right) \hat{\beta}_{h}}_{\text {Efeito Dotação }}+\underbrace{\bar{X}_{m}\left(\hat{\beta}_{m}-\hat{\beta}_{h}\right)}_{\text {Efeito Discriminação }} \\
& \ln \bar{W}_{n b}-\ln \bar{W}_{b}=\underbrace{\left(\bar{X}_{n b}-\bar{X}_{b}\right) \hat{\beta}_{b}}_{\text {Efeito Dotação }}+\underbrace{\bar{X}_{n b}\left(\hat{\beta}_{n b}-\hat{\beta}_{b}\right)}_{\text {Efeito Discriminação }}
\end{aligned}
$$

\subsubsection{Decomposição de Ñopo (2008)}

Em alternativa a decomposição de Oxaca-Blinder, Ñopo (2008) desenvolve um modelo não paramétrico que utiliza técnicas de pareamento para explicar os diferenciais de rendimentos entre gêneros e não requer a estimação da equação de rendimentos para comparação entre grupos distintos. Segundo o autor, existe um problema de má especificação devido às diferenças nos suportes das distribuições empíricas de características individuais para os grupos analisados. Dessa forma, por não considerar esta restrição, a decomposição de Oaxaca-Blinder é baseada implicitamente em uma "suposição fora do suporte comum", tornando-se necessário assumir que os estimadores lineares das equações de rendimento também são válidos fora dos suportes. Nopo argumenta que a evidência empírica sugere que essa suposição tende a superestimar o componente "gap" atribuído as diferenças nos ganhos. Nesta metodologia, o diferencial é calculado a partir do valor esperado dos ganhos condicionados às características observáveis (relacionadas a esses ganhos) e da função de distribuição acumulada das características observáveis.

Considere Y uma variável aleatória dos rendimentos individuais, X um vetor de características, tais como, educação, experiência e raça. Seja $F^{M}(). e F^{F}($.$) , as funções de distribuição acumulada condicional, dado$ 
que o indivíduo é do sexo masculino e feminino, ${ }^{14}$ respectivamente, e $F^{M}() e. d F^{F}($.$) as respectivas medidas de probabilidades.$

$\mathrm{O}$ valor esperado dos rendimentos, condicionado às características e gênero, é representado por $g^{M}(). e g^{F}($.$) , ou seja,$

$$
\begin{aligned}
& E[Y \mid M]=\int_{S^{M}} g^{M}(x) d F^{M}(x) \\
& E[Y \mid F]=\int_{S^{F}} g^{F}(x) d F^{F}(x)
\end{aligned}
$$

Onde $S^{M}$ e $S^{F}$ denotam o suporte de distribuição de características para homens e mulheres, respectivamente. Dessa forma, o diferencial entre os salários é definido por:

$$
\begin{aligned}
& \Delta=E[Y \mid M]-E[Y \mid F] \\
& \Delta=\int_{S^{M}} g^{M}(x) d F^{M}(x)-\int_{S^{F}} g^{F}(x) d F^{F}(x)
\end{aligned}
$$

Considerando que o suporte da distribuição de características para as mulheres, $S^{F}$, difere do suporte para os homens, $S^{M}$, cada integral na Equação (10) é decomposta em dois termos, dentro e fora do suporte comum e, assim, os termos pertencentes ao suporte podem ser interpretados de forma tradicional como na decomposição de Oaxaca-Blinder. Dessa forma, o diferencial é decomposto em quatro componentes, considerando as diferenças salariais entre homens e mulheres dentro e fora do suporte comum, o qual pode ser observado na equação abaixo.

$$
\Delta=\Delta_{M}+\Delta_{X}+\Delta_{0}+\Delta_{F} 15
$$

O primeiro termo, $\Delta_{M}$ é a parte do diferencial que pode ser explicado pelas diferenças entre os grupos de homens, os que possuem características que podem ser pareadas com as características das mulheres, e outro que não pode. Este componente seria igual a zero caso não houvesse homens não pareados com mulheres e pode ser encontrado através da diferença entre os

\footnotetext{
${ }^{14}$ Neste estudo, essas funções também serão representadas para raça, onde o grupo das mulheres será denotado como o grupo de não branco e o grupo dos homens denotará o grupo dos brancos.

${ }^{15} \mathrm{Na}$ análise para raça, a decomposição será representada da seguinte forma: $\Delta=\left(\Delta_{B}+\Delta_{X}+\Delta_{N B}\right)+\Delta_{0}$
} 
salários esperados dos homens dentro e fora do suporte comum, ponderado pela probabilidade medida pelo conjunto de características que as mulheres não possuem. O segundo componente, $\Delta_{X}$, capta o diferencial explicado por características entre homens e mulheres que se encontram dentro do suporte comum e possui interpretação equivalente ao termo $\underbrace{\left(\bar{X}_{A}-\bar{X}_{B}\right) \hat{\beta}_{B}}_{\text {Efeto }}$ da decomposição de Oaxaca-Blinder.

Efeito Dotação

O termo $\Delta_{0}$ representa a parte não explicada do diferencial, interpretação equivalente ao componente $\bar{X}_{A}\left(\hat{\beta}_{A}-\hat{\beta}_{B}\right)$ de Oaxaca-blinder. Por fim, o quarto termo, $\Delta_{F}$ possui interpretação semelhante ao primeiro termo, porém, para mulheres.

Nopo (2008) afirma que três dos componentes podem ser atribuídos à existência de diferenças nas características individuais $\Delta_{M}, \Delta_{X}$ e $\Delta_{F}$ e o outro, $\Delta_{0}$, refere-se a diferenças de características não observáveis, capturando uma combinação entre essas diferenças premiadas pelo mercado de trabalho e, eventualmente, discriminação (no contexto de diferenciais raciais ou por gênero). Dessa forma, o diferencial de salários pode ser expresso por:

$$
\Delta=\left(\Delta_{M}+\Delta_{X}+\Delta_{F}\right)+\Delta_{0}
$$

O procedimento do matching para a estimação desses quatro componentes se dá a partir da construção de uma nova amostra, em que para todas as mulheres, sem reposição, é criado um homem sintético, com as mesmas características observáveis, cujo salário é obtido pela média de todos os homens com exatamente as mesmas características X. Nopo (2008) considera somente as características que podem ser descritas como variáveis discretas e de matching perfeito. ${ }^{16} \mathrm{O}$ algoritmo de pareamento pode ser sumarizado da seguinte forma: 1) Uma mulher é selecionada da amostra, sem reposição; 2) Selecionam-se todos os homens com características observáveis semelhantes às mulheres previamente selecionadas na primeira etapa; 3) Com todos os indivíduos selecionados na etapa, constrói-se um "indivíduo sintético", cujas características sejam iguais à média de todos aqueles selecionados na etapa 2 , e pareia-se este indivíduo sintético a mulher da etapa 1; 4) Inserem-se as observações de ambos os indivíduos sintéticos na nova amostra de indivíduos pareados; 5) Repete-se o procedimento para cada mulher.

${ }^{16}$ A condição de matching perfeito e domínio discreto pode ser relaxada até certo ponto. Isso exigiria a introdução de alguma noção de distância e uma tolerância para a distância máxima aceitável para os dois conjuntos de características a serem consideradas no matching. 
A partir desse procedimento, será gerada uma partição desse conjunto de dados, na qual irá conter observações das mulheres e homens pareados e não pareados, em que os pareados terão a mesma distribuição de probabilidade para as características X. Segundo Nopo (2008), o objetivo da reamostragem sem substituição da amostra de mulheres e com reposição da amostra dos homens é para preservar a distribuição empírica das características das mulheres. Além disso, a utilização deste critério de matching evita qualquer hipótese paramétrica sobre as variáveis aleatórias incluídas no modelo, pois baseia-se unicamente na suposição de que indivíduos com mesmas características observáveis devem ser remunerados da mesma forma que o sexo oposto.

Esta análise questiona um ponto importante na decomposição de $\mathrm{OB}$, o qual não recebeu atenção considerável, mas desempenha um papel importante: os suportes das distribuições de características para mulheres e homens não podem se sobrepor completamente, sendo necessária a restrição da decomposição em termos de diferenças características e diferenças nos coeficientes no suporte comum, em que a comparação dos salários é apropriada. Usando a decomposição de OB é preciso, implicitamente, fazer suposições fora do suporte comum sobre os estimadores obtidos pela regressão, porém, embora pareçam plausíveis, não há provas que as sustentem, diferentemente da decomposição proposta por Nopo (2008), a qual não é necessário fazer hipóteses desse tipo. Além disso, o método permite encontrar o gap de rendimentos que corresponde ao intervalo que não possui a sobreposição, $\Delta_{F} e \Delta_{M}$.

Independente de raça ou gênero, indivíduos com características semelhantes deveriam ser remunerados igualmente no mercado de trabalho, ou seja, deveria ser zero. Dessa forma, este trabalho optou por decompor o diferencial de rendimento entre gêneros e entre raças, utilizando o procedimento de Ñopo (2008), considerando as diferentes categorias ocupacionais para as regiões metropolitanas, porém, para o Brasil, será realizada uma comparação com a decomposição de Oaxaca-Blinder (1973), objetivando constatar que esta apresenta efeitos superestimados. Nesta análise, consideram-se todas as variáveis apresentadas no Quadro 1, de características pessoais, mercado de trabalho, atividades, ocupações e regionais. Logo em seguida, serão desagregadas por ocupações e por regiões metropolitanas, permanecendo as demais variáveis. 


\section{Análise e Discussão dos Resultados}

\subsection{Estatísticas Descritivas}

Após apresentar a metodologia e a origem das variáveis utilizadas, faz-se pertinente realizar uma análise descritiva dos dados para se ter, inicialmente, algumas evidências sobre o diferencial de salários, tanto por gênero quanto por raça, no mercado de trabalho metropolitano. A Tabela 2 contempla as estatísticas descritivas para cada uma das variáveis utilizadas neste estudo.

Tabela 2 - Estatísticas descritivas das variáveis, Brasil Metropolitano 2014

\begin{tabular}{|c|c|c|c|c|c|c|c|c|}
\hline \multirow{2}{*}{ Variáveis } & \multicolumn{2}{|c|}{ Não Branco } & \multicolumn{2}{|c|}{ Branco } & \multicolumn{2}{|c|}{ Mulheres } & \multicolumn{2}{|c|}{ Homens } \\
\hline & Média & SD & Média & SD & Média & SD & Média & SD \\
\hline Renda-ICV & 878.32 & 1661.77 & 1527.18 & 3171.86 & 771.26 & 1801.00 & 1585.55 & 2973.43 \\
\hline Educ & 9.76 & 3.82 & 11.12 & 3.83 & 10.59 & 3.87 & 10.16 & 3.88 \\
\hline Experiência & 20.44 & 13.40 & 21.17 & 13.60 & 19.06 & 13.12 & 21.99 & 13.63 \\
\hline Sexo & 0.49 & 0.50 & 0.52 & 0.50 & 0.53 & 0.50 & 0.56 & 0.50 \\
\hline Casado & 0.04 & 0.20 & 0.03 & 0.18 & 0.04 & 0.19 & 0.04 & 0.19 \\
\hline Sindicalizado & 0.13 & 0.34 & 0.16 & 0.37 & 0.13 & 0.34 & 0.15 & 0.36 \\
\hline Emprego Formal & 0.81 & 0.39 & 0.83 & 0.37 & 0.82 & 0.38 & 0.82 & 0.38 \\
\hline Componentes Familiares & 3.43 & 1.42 & 3.25 & 1.27 & 3.33 & 1.34 & 3.37 & 1.37 \\
\hline Horas Trab. na Semana & 41.19 & 11.31 & 41.25 & 11.54 & 39.07 & 11.90 & 42.65 & 10.85 \\
\hline Indústria & 0.29 & 0.45 & 0.25 & 0.43 & 0.16 & 0.36 & 0.35 & 0.48 \\
\hline Dirigentes & 0.04 & 0.20 & 0.09 & 0.29 & 0.06 & 0.24 & 0.07 & 0.25 \\
\hline Ciências das Artes & 0.06 & 0.24 & 0.15 & 0.35 & 0.13 & 0.34 & 0.08 & 0.27 \\
\hline Serviços & 0.82 & 0.38 & 0.66 & 0.48 & 0.72 & 0.45 & 0.77 & 0.42 \\
\hline Técnicos & 0.07 & 0.26 & 0.10 & 0.30 & 0.09 & 0.28 & 0.09 & 0.28 \\
\hline Comércio e Serviços & 0.42 & 0.49 & 0.40 & 0.49 & 0.41 & 0.49 & 0.41 & 0.49 \\
\hline Social & 0.14 & 0.34 & 0.16 & 0.37 & 0.26 & 0.44 & 0.08 & 0.27 \\
\hline RM-Belém & 0.10 & 0.30 & 0.04 & 0.20 & 0.08 & 0.26 & 0.07 & 0.26 \\
\hline RM-Fortaleza & 0.11 & 0.31 & 0.06 & 0.23 & 0.08 & 0.28 & 0.08 & 0.28 \\
\hline RM-Recife & 0.13 & 0.34 & 0.08 & 0.27 & 0.11 & 0.31 & 0.10 & 0.31 \\
\hline RM-Salvador. & 0.15 & 0.35 & 0.03 & 0.17 & 0.09 & 0.29 & 0.09 & 0.29 \\
\hline RM-Belo Horizonte & 0.11 & 0.31 & 0.08 & 0.26 & 0.09 & 0.29 & 0.10 & 0.30 \\
\hline RM-Rio de Janeiro & 0.14 & 0.34 & 0.14 & 0.35 & 0.14 & 0.35 & 0.14 & 0.34 \\
\hline RM-Distrito Federal & 0.07 & 0.26 & 0.05 & 0.23 & 0.06 & 0.25 & 0.06 & 0.24 \\
\hline RM-Porto Alegre & 0.03 & 0.16 & 0.09 & 0.29 & 0.06 & 0.23 & 0.06 & 0.23 \\
\hline RM-Curitiba & 0.04 & 0.21 & 0.23 & 0.42 & 0.13 & 0.33 & 0.13 & 0.33 \\
\hline RM-São Paulo & 0.12 & 0.33 & 0.20 & 0.40 & 0.15 & 0.36 & 0.16 & 0.37 \\
\hline
\end{tabular}

Nota: DP = Desvio Padrão.

Fonte: Elaboração própria a partir dos dados da pesquisa. 
De acordo com essa tabela, verifica-se que existe diferença salarial, tanto por gênero quanto por raça. Na comparação entre os gêneros, os homens possuem, em média, maiores rendimentos que as mulheres, mesmo estas possuindo níveis de escolaridade mais elevados. Já na análise por raça, observa-se que os brancos possuem, em média, maiores níveis educacionais e maiores rendimentos que os não brancos. Com relação à experiência, constata-se que homens e brancos apresentaram-se como mais experientes, quando comparados às mulheres e não brancos, respectivamente.

Verifica-se também que o mercado de trabalho apresenta um nível considerável de formalização, uma vez que este varia de $81 \%$ a $83 \%$, corroborando com as estatísticas apresentadas na introdução. Além disso, constata-se que os homens trabalham, em média, mais horas que as mulheres, e que esta diferença é de aproximadamente 3 horas por semana. Já na análise por raça, observa-se que em média os brancos trabalham mais que os não brancos, no entanto, esta diferença média não chega a ser superior a 1 hora por semana.

No tocante aos setores econômicos, a maioria dos trabalhadores está atuando no setor serviços, mais especificamente no grupo de comércio e serviços. Quanto às variáveis referentes ao estado civil e à sindicalização dos trabalhadores, pode-se aferir que, em média, apenas 4\% dos profissionais analisados neste estudo são casados e que, em média, de $13 \%$ a $16 \%$ são sindicalizados. Além disso, verifica-se que a amostra está relativamente distribuída entre as regiões metropolitanas. Além disso, observa-se que a distribuição de homens e mulheres é bem equivalente nas RMs, no entanto, há uma predominância de trabalhadores não brancos, exceto nas regiões metropolitanas do Rio de Janeiro, Curitiba, Porto Alegre e São Paulo.

Ao analisar brevemente os resultados descritivos da amostra, nota-se que existem diferenças salariais tanto por gênero quanto por raça, e que tais disparidades podem estar associadas à presença de discriminação, principalmente na análise entre os gêneros, uma vez que os homens recebem maiores salários do que as mulheres, mas estas possuem maiores níveis educacionais. No entanto, tais evidências não podem atestar a existência de uma possível discriminação entre os gêneros e raças nas RM's. Diante do exposto, a próxima seção apresentará os resultados obtidos pelas estimações com vistas a verificar se este comportamento é devido à presença de discriminação no mercado de trabalho ou se estar associada a fatores relacionados à produtividade dos indivíduos. 


\subsection{Análise das Diferenças Salariais: Brasil Metropolitano}

O pareamento é utilizado no modelo de Ñopo para se obter o diferencial de rendimentos entre os grupos analisados, a partir de características similares entre eles, ou seja, o cálculo do diferencial de rendimentos é feito dentro de um suporte comum. ${ }^{17} \mathrm{~A}$ Tabela 3 mostra os resultados das estimações de Nopo (2008) e Oaxaca-Blinder (1973). Como já mencionado, o foco principal deste artigo é mensurar a discriminação através do pareamento de semelhantes. Entretanto, foram calculados os efeitos decomposição de Oaxaca, por se tratar do método mais utilizado na literatura para determinação do efeito discriminação entre gêneros e entre raças no mercado de trabalho (Giuberti; Menezes-Filho 2005; Souza; Camara 2005; Carvalho; Neri; Silva 2006; Cacciamali; Tatei; Rosalino 2008; Freisleben; Bezerra 2012; Souza et. al. 2015; Gomes; Souza 2016), bem como, para que seja possível verificar se os resultados obtidos superestimam o diferencial entre os grupos analisados. Contudo, a análise será realizada principalmente para o modelo de Ñopo.

As estimações de Nopo e Oaxaca para o Brasil metropolitano foram realizadas com a finalidade de verificar a magnitude do diferencial e os impactos dos efeitos dotações e discriminação nas equações de rendimento, utilizando as variáveis recorrentes na literatura, descritas no Quadro 1. Dessa forma, foi estimada a equação de rendimentos completa para gênero e raça, considerando as seguintes ocupações, dirigentes, serviços, técnicos e profissionais das ciências e das artes.

Comparando os dois modelos, verifica-se que existe uma superestimação dos diferenciais de rendimentos (efeito total), tanto para sexo quanto para raça, quando examinado o modelo de Oaxaca para todas as categorias consideradas, corroborando os resultados obtidos por Nopo (2008). Esses resultados demostram que, ao utilizar esse método, possivelmente incorre-se no viés de má especificação, comprometendo, assim, a análise dos resultados, uma vez que esses diferenciais superestimados podem estar relacionados a outras características pessoais, regionais ou voltadas ao mercado de trabalho dos trabalhadores, tais como escolaridade, experiência, setor de trabalho, os tipos de atividades, as horas trabalhadas, dentre outras, já que esse método não considera um pareamento dessas variáveis.

\footnotetext{
${ }^{17}$ Por restrições de páginas, os autores omitiram a tabela com os percentuais de indivíduos dentro do suporte comum, considerando as categorias ocupacionais e as regiões metropolitanas. Para mais detalhes, entrar em contato com os autores.
} 
A partir dessa comprovação, todas as demais análises dos resultados desse trabalho serão feitas pelo método de Nopo, inclusive para o Brasil metropolitano, expostos na tabela abaixo.

Avaliando a decomposição por gênero com as ocupações agrupadas, percebe-se que o efeito das características observáveis atua no sentido de diminuir o diferencial de rendimentos entre as mulheres e os homens, enquanto que o efeito discriminatório (D0) age de forma a aumentar essa diferença. Ressalta-se ainda que, dentro do suporte comum, as características observáveis (DX) pouco explicam os diferenciais, uma vez que todas as variáveis foram pareadas. Além disso, o valor desse efeito é próximo de zero, denotando que houve um bom pareamento nas características individuais; porém, observa-se que o termo que representa o diferencial de rendimento dentro dos grupos dos homens, o qual compara aqueles que puderam ser pareados com os que não foram, (DM), apresentou o maior efeito sobre os diferenciais nas características observáveis. 
Tabela 3 - Decomposição de Ñopo (2008) e Oaxaca e Blinder (1973) por Sexo e Raça - Brasil, 2014

\begin{tabular}{|c|c|c|c|c|c|c|}
\hline \multicolumn{7}{|c|}{ Sexo } \\
\hline & Efeitos & Todas & Dirigentes & Serviços & Técnicos & Ciências e das artes \\
\hline \multirow{9}{*}{ Ñopo } & DF & 0.0071 & 0.0045 & -0.0049 & 0.0091 & 0.0110 \\
\hline & Do & -0.1086 & -0.0593 & -0.1241 & -0.0901 & -0.0907 \\
\hline & DX & 0.0022 & 0.0007 & 0.0047 & -0.0005 & 0.0006 \\
\hline & DM & 0.0509 & 0.0065 & 0.0692 & 0.0333 & 0.0214 \\
\hline & \multirow{2}{*}{ Observáveis } & 0.0602 & 0.0117 & 0.0690 & 0.0419 & 0.0330 \\
\hline & & $-124.84 \%$ & $-24.63 \%$ & $-125.23 \%$ & $-87.32 \%$ & $-57.49 \%$ \\
\hline & \multirow{2}{*}{ Não observáveis } & -0.1086 & -0.0593 & -0.1241 & -0.0901 & -0.0907 \\
\hline & & $224.84 \%$ & $124.63 \%$ & $225.23 \%$ & $187.32 \%$ & $157.49 \%$ \\
\hline & TOT & -0.0483 & -0.0475 & -0.0551 & -0.0481 & -0.0574 \\
\hline \multirow{5}{*}{ Oaxaca } & \multirow{2}{*}{ Observáveis } & 0.0604 & -0.0219 & 0.0333 & -0.0446 & -0.0809 \\
\hline & & $-33.57 \%$ & $6.84 \%$ & $-16.10 \%$ & $17.11 \%$ & $23.46 \%$ \\
\hline & \multirow{2}{*}{ Não observáveis } & -0.2403 & -0.2998 & -0.2402 & -0.2161 & -0.2640 \\
\hline & & $133.57 \%$ & $93.16 \%$ & $116.10 \%$ & $82.89 \%$ & $76.54 \%$ \\
\hline & TOT & -0.1799 & -0.3218 & -0.2068 & -0.2607 & -0.3449 \\
\hline \multicolumn{7}{|c|}{ Raça } \\
\hline \multirow{9}{*}{ Ñopo } & DNB & -0.0064 & 0.0020 & -0.0265 & 0.0016 & 0.0029 \\
\hline & Do & -0.0689 & -0.0537 & -0.0244 & -0.0659 & -0.0828 \\
\hline & DX & -0.0001 & 0.0000 & -0.0021 & 0.0002 & 0.0018 \\
\hline & DB & 0.0242 & -0.0054 & 0.0303 & 0.0221 & 0.0229 \\
\hline & & 0.0177 & -0.0034 & 0.0017 & 0.0239 & 0.0276 \\
\hline & (2) & $-34.50 \%$ & $5.95 \%$ & $-7.46 \%$ & $-57.18 \%$ & $-50.09 \%$ \\
\hline & Ñ̃ & -0.0689 & -0.0537 & -0.0244 & -0.0659 & -0.0828 \\
\hline & 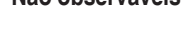 & $134.50 \%$ & $94.05 \%$ & $107.46 \%$ & $157.18 \%$ & $150.09 \%$ \\
\hline & TOT & -0.0513 & -0.0571 & -0.0228 & -0.0418 & -0.0551 \\
\hline \multirow{5}{*}{ Oaxaca } & \multirow{2}{*}{ Observáveis } & 0.2337 & 0.3254 & 0.0849 & 0.1133 & 0.1347 \\
\hline & & $73.63 \%$ & $65.21 \%$ & $58.67 \%$ & $43.13 \%$ & $39.05 \%$ \\
\hline & \multirow{2}{*}{ Não observáveis } & 0.0837 & 0.1736 & 0.0598 & 0.1494 & 0.2101 \\
\hline & & $26.37 \%$ & $34.79 \%$ & $41.33 \%$ & $56.87 \%$ & $60.92 \%$ \\
\hline & TOT & 0.3174 & 0.4990 & 0.1447 & 0.2627 & 0.3449 \\
\hline
\end{tabular}

Notas: (a) todos os resultados foram estatisticamente significantes a menos de 1\%; (b) TOT: Diferencial Total; c) Efeito de características observáveis em Nopo: DM (DB) + DX+ DF(DNB) sendo que: DF $(D N B)=$ É a parte do hiato salarial que pode ser explicada pelas diferenças de características entre os trabalhadores do sexo feminino (raça: não brancos) que estão dentro e fora do suporte comum. DM $(D B)=$ É a parte do hiato salarial que pode ser explicada pelas diferenças de características entre os trabalhadores do sexo masculino (raça: brancos), que estão dentro e fora do suporte comum. DX= Capta o diferencial explicado por características entre mulheres (raça: não brancos) e homens (raça: brancos) que se encontram dentro do suporte comum. Efeito de características não observáveis: D0. d) Efeito de características observáveis em Oaxaca é o próprio efeito dotação.

Fonte: Elaboração própria a partir dos dados da pesquisa. 
Com relação à raça, verifica-se que o efeito discriminatório age no sentido de aumentar o "gap" existente entre os brancos e não brancos, e o efeito das características observáveis age reduzindo esse diferencial. Vale ressaltar que o termo (DB) foi o responsável por tornar esse efeito positivo, ou seja, a parte do diferencial que pode ser explicada pelas diferenças entre os grupos dos brancos, os que possuem características que podem ser pareadas com as características dos não brancos, e outro que não pode. Ademais, o efeito discriminatório tem um impacto maior na diferença salarial, tanto na raça quanto por gênero, entre os grupos. Além disso, o efeito dotação dentro do suporte comum (DX) foi próximo a zero, comprovando que as características observadas foram pareadas entre os indivíduos brancos e não brancos.

Desagregando as ocupações, a análise por gênero indica que a categoria dirigentes possui o menor efeito de características observáveis, seguido dos profissionais das ciências e das artes, enquanto que a categoria dos serviços apresenta o maior efeito. Esses resultados indicam que embora as mulheres apresentem dotações superiores aos homens em todas as categorias, em ocupações que apresentam maiores rendimentos e que são compostas por trabalhadores com maiores níveis educacionais, esse efeito é menor, ou seja, os homens apresentam dotações próxima às das mulheres nessas categorias, enquanto que nas demais ocupações, o efeito de características observáveis das mulheres age de forma mais forte em reduzir os diferenciais de rendimentos.

Por outro lado, o efeito discriminatório é sempre superior para todas as ocupações, agindo para aumentar o diferencial de rendimentos, com destaque para as ocupações serviços, seguido dos técnicos, corroborando os resultados encontrados por Gomes e Souza (2016), os quais afirmaram que apesar da maior absorção do trabalho feminino nos setores de Comércio e Serviços, ainda assim, nesses setores, existe discriminação de rendimentos contra as mulheres em um menor grau no comércio e maior no serviços. Porém, a categoria dos profissionais das ciências e das artes é a ocupação com maiores diferenciais de rendimentos entre homens e mulheres.

Analisando as ocupações por raça, com relação aos efeitos de características observáveis, apenas a categoria dos dirigentes apresentou efeito negativo, sobre o qual atua aumentando o diferencial de rendimentos entre brancos e não brancos; porém, esse valor é próximo a zero. Em termos absolutos, observa-se que a ocupação de serviços é a que apresenta o maior 
diferencial de rendimentos dentro do grupo dos brancos (DB), entre aqueles que forma pareados com os que não foram. Quanto ao efeito discriminação (D0), este apresentou-se mais forte para a categoria dos técnicos e profissionais das ciências e das artes, enquanto que os dirigentes apresentaram-se como a categoria com menor efeito discriminação sobre os diferenciais de rendimentos.

Como pode ser verificado, os resultados obtidos pelas estimações mostraram que o modelo de Oaxaca-Blinder superestima os diferenciais de rendimentos, gerando um viés que mascara a real diferença salarial entre mulheres e homens e não brancos e brancos para as ocupações agrupadas e para cada categoria analisada. Além disso, o modelo de Ñopo mostrou que para o Brasil metropolitano os resultados seguem a literatura nacional e internacional. Ademais, a categoria dos dirigentes é a que apresenta maior desigualdade salarial, entre raças, e a ocupação dos profissionais das ciências e das artes, entre gêneros, porém, a ocupação dos serviços é a que mais discrimina entre os gêneros, e os técnicos, entre as raças.

\subsection{Análise das Diferenças Salariais por Ocupações e RM: Comparação entre os Gêneros}

De acordo com a Tabela 4, as diferenças salariais apresentam valores semelhantes em cada grupo. Entretanto, a ocupação dos profissionais das ciências e das artes é aquela que tem as maiores diferenças salariais nas RMs, com destaque para: Salvador, Belo Horizonte e Curitiba, sendo que o maior efeito total ocorre para a região metropolitana de Salvador $(-0,1071)$. Com relação aos componentes que explicam a diferença salarial, a maioria das ocupações e regiões metropolitanas seguem o seguinte padrão: o efeito das características observáveis $(\mathrm{DF}+\mathrm{DM}+\mathrm{DX})$ age como um redutor do diferencial. Entretanto, o efeito dotação (DX) é zero ou próximo de zero em todas as ocupações, denotando que o pareamento deixou os grupos muito semelhantes com relação às características individuais; ${ }^{18} \mathrm{o}$ efeito discriminação (D0), relacionado apenas à característica de ser mulher, age no sentido de aumentar a disparidade entre homes e mulheres, excetuando-se a RM do Rio de Janeiro para a ocupação dos profissionais das ciências e das artes.

${ }^{18} \mathrm{O}$ objetivo do modelo de Nopo é parear os grupos afim deque esses grupos tenho características observáveis muito semelhantes. 
Para o grupo de dirigentes, os resultados indicam que dada as características dessa ocupação (grupo com alto nível educacional, bem como elevada experiência), a diferença salarial positiva para os trabalhadores do sexo masculino está presente em todas as RMs, sendo que Fortaleza apresenta o maior diferencial total $(-0,664)$ e o Rio de Janeiro com o menor diferencial total $(-0,0218)$. O efeito das características individuais dentro do suporte comum (efeito dotação) na busca de diminuir o diferencial salarial entre mulheres e homens foi próximo de zero, e o efeito das características não observáveis (efeito discriminação) acompanhou os resultados obtidos no efeito total.

Com relação aos profissionais das ciências e das artes, ${ }^{19}$ os efeitos no diferencial total atuam de forma distinta entre as regiões, sendo que a região metropolitana de Salvador obteve o maior efeito total na diferença salarial sobre o mercado de trabalho e Rio de Janeiro com menor efeito. Nessa ocupação, tem-se professores, juízes, advogados, engenheiros, médicos, entre outras profissões, que exigem maior acumulação de capital humano, denotando que mesmo para aqueles com maiores níveis educacionais a discriminação atua sempre em favor dos trabalhadores do sexo masculino, com exceção da região metropolitana do Rio de Janeiro, cujo efeito discriminação foi positivo, porém próximo a zero. As demais RM obtiveram os efeitos esperados.

${ }^{19}$ Pesquisadores e profissionais policientíficos; profissionais das ciências exatas, físicas e da engenharia; profissionais das ciências biológicas, da saúde e afins; profissionais do ensino; profissionais das ciências jurídicas; profissionais das ciências sociais e humanas; comunicadores, artistas e religiosos; profissionais em gastronomia. 
Tabela 4 - Decomposição de Ñopo (2008) por Sexo e Regiões Metropolitanas, 2014 Ocupações desagrupadas

\begin{tabular}{|c|c|c|c|c|c|c|c|c|c|c|}
\hline \multirow{2}{*}{ Efeitos } & \multicolumn{10}{|c|}{ Dirigentes } \\
\hline & RMB & RMF & RMR & RMS & RBH & RRJ & RSP & RMC & RMPOA & $\mathrm{DF}$ \\
\hline DF & 0,0148 & 0,0012 & 0,0228 & 0,0230 & 0,0037 & 0,0214 & 0,0172 & 0,0242 & 0,0056 & $-0,0044$ \\
\hline Do & $-0,0821$ & $-0,1017$ & $-0,0408$ & $-0,0792$ & $-0,0364$ & $-0,0167$ & $-0,0649$ & $-0,0777$ & $-0,0618$ & $-0,0673$ \\
\hline DX & 0,0000 & 0,0000 & $-0,0002$ & 0,0000 & 0,0000 & 0,0000 & $-0,0001$ & 0,0000 & $-0,0017$ & 0,0000 \\
\hline DM & 0,0222 & 0,0335 & $-0,0046$ & $-0,0103$ & $-0,0017$ & $-0,0265$ & 0,0122 & $-0,0032$ & 0,0022 & 0,0199 \\
\hline \multirow{2}{*}{ Observáveis } & 0,0370 & 0,0346 & 0,0180 & 0,0127 & 0,0020 & $-0,0051$ & 0,0292 & 0,0210 & 0,0061 & 0,0155 \\
\hline & $-82,1 \%$ & $-51,7 \%$ & $-78,7 \%$ & $-19,2 \%$ & $-5,9 \%$ & $23,4 \%$ & $-82,0 \%$ & $-37,0 \%$ & $-11,0 \%$ & $-29,8 \%$ \\
\hline \multirow{2}{*}{ Não observáveis } & $-0,0821$ & $-0,1017$ & $-0,0408$ & $-0,0792$ & $-0,0364$ & $-0,0167$ & $-0,0649$ & $-0,0777$ & $-0,0618$ & $-0,0673$ \\
\hline & $182,07 \%$ & $151,69 \%$ & $178,71 \%$ & $119,18 \%$ & $105,88 \%$ & $76,55 \%$ & $182,03 \%$ & $137,01 \%$ & $111,04 \%$ & $129,80 \%$ \\
\hline TOT & $-0,0451$ & $-0,0670$ & $-0,0228$ & $-0,0664$ & $-0,0344$ & $-0,0218$ & $-0,0357$ & $-0,0567$ & $-0,0556$ & \\
\hline \multicolumn{11}{|c|}{ Profissionais das Ciências e das Artes } \\
\hline DF & $-0,0028$ & $-0,0522$ & 0,0019 & 0,0402 & $-0,0151$ & $-0,0182$ & 0,0097 & 0,0142 & 0,0303 & 0,0274 \\
\hline Do & $-0,1508$ & $-0,1077$ & $-0,1474$ & $-0,2512$ & $-0,1189$ & 0,0027 & $-0,0817$ & $-0,1359$ & $-0,0985$ & $-0,0841$ \\
\hline DX & 0,0000 & 0,0000 & 0,0000 & $-0,0001$ & 0,0000 & 0,0000 & 0,0000 & 0,0000 & 0,0000 & 0,0011 \\
\hline DM & 0,0905 & 0,1075 & 0,0828 & 0,1041 & 0,0367 & $-0,0209$ & 0,0295 & 0,0455 & 0,0096 & 0,0086 \\
\hline \multirow{2}{*}{ Observáveis } & 0,0876 & 0,0552 & 0,0848 & 0,1442 & 0,0216 & $-0,0391$ & 0,0391 & 0,0597 & 0,0399 & 0, \\
\hline & $-138,7 \%$ & $-105,3 \%$ & $-135,3 \%$ & $-134,6 \%$ & $-22,17 \%$ & $107,41 \%$ & $-91,92 \%$ & $-78,35 \%$ & $-68,16 \%$ & $-78,81 \%$ \\
\hline \multirow{2}{*}{ Não observáveis } & $-0,1508$ & $-0,1077$ & $-0,1474$ & $-0,2512$ & $-0,1189$ & 0,0027 & $-0,0817$ & $-0,1359$ & $-0,0985$ & $-0,0$ \\
\hline & $238,73 \%$ & $205,35 \%$ & $235,37 \%$ & $234,63 \%$ & $122,17 \%$ & $-7,41 \%$ & $191,92 \%$ & $178,35 \%$ & $168,16 \%$ & $178,81 \%$ \\
\hline TOT & $-0,0632$ & $-0,0524$ & $-0,0626$ & $-0,1071$ & $-0,0974$ & $-0,0364$ & $-0,0426$ & $-0,0762$ & $-0,0585$ & $-0,0471$ \\
\hline \multicolumn{11}{|c|}{ Técnicos } \\
\hline DF & $-0,0123$ & $-0,0016$ & $-0,0108$ & $-0,0404$ & 0,0036 & $-0,0030$ & 0,0473 & 0,0068 & 0,0034 & 0,0194 \\
\hline Do & $-0,0297$ & $-0,1007$ & $-0,1249$ & $-0,0363$ & $-0,0661$ & $-0,0462$ & $-0,1427$ & $-0,1220$ & $-0,0436$ & $-0,1044$ \\
\hline DX & 0,0000 & 0,0000 & $-0,0010$ & $-0,0002$ & 0,0000 & $-0,0002$ & 0,0000 & $-0,0053$ & $-0,0018$ & 0,0000 \\
\hline DM & 0,0108 & 0,0626 & 0,0616 & 0,0219 & 0,0197 & 0,0143 & 0,0411 & 0,0623 & $-0,0031$ & 0,0339 \\
\hline \multirow{2}{*}{ Observáveis } & $-0,0015$ & 0,0610 & 0,0499 & $-0,0187$ & 0,0233 & 0,0111 & 0,0884 & 0,0638 & $-0,0015$ & 0,0533 \\
\hline & $4,80 \%$ & $-153,4 \%$ & $-66,45 \%$ & $33,95 \%$ & $-54,22 \%$ & $-31,70 \%$ & $-163,0 \%$ & $-109,4 \%$ & $3,37 \%$ & $-104,2 \%$ \\
\hline \multirow{2}{*}{ Não observáveis } & $-0,0297$ & $-0,1007$ & $-0,1249$ & $-0,0363$ & $-0,0661$ & $-0,0462$ & $-0,1427$ & $-0,1220$ & $-0,0436$ & $-0,1044$ \\
\hline & $95,20 \%$ & $253,44 \%$ & $166,45 \%$ & $66,05 \%$ & $154,22 \%$ & $131,70 \%$ & $263,04 \%$ & $209,48 \%$ & $96,63 \%$ & $204,27 \%$ \\
\hline TOT & $\mid-0,0312$ & $-0,0397$ & $-0,0751$ & $-0,0550$ & $-0,0429$ & $-0,0351$ & $-0,0542$ & $-0,0582$ & $-0,0451$ & $-0,0511$ \\
\hline \multicolumn{11}{|c|}{ Serviços } \\
\hline DF & $-0,014$ & $-0,014$ & $-0,011$ & $-0,029$ & 0,007 & $-0,001$ & 0,004 & 0,007 & $-0,012$ & 0,000 \\
\hline Do & $-0,065$ & $-0,129$ & $-0,116$ & $-0,107$ & $-0,160$ & $-0,080$ & $-0,112$ & $-0,122$ & $-0,110$ & $-0,123$ \\
\hline DX & $-0,001$ & $-0,003$ & $-0,009$ & $-0,002$ & $-0,002$ & $-0,001$ & $-0,002$ & $-0,005$ & $-0,007$ & $-0,004$ \\
\hline DM & 0,036 & 0,080 & 0,079 & 0,074 & 0,081 & 0,035 & 0,064 & 0,062 & 0,077 & 0,074 \\
\hline \multirow{2}{*}{ Observáveis } & 0,0214 & 0,0637 & 0,0592 & 0,0424 & 0,0862 & 0,0325 & 0,0660 & 0,0638 & 0,0578 & 0,0700 \\
\hline & $-48,98 \%$ & $-97,12 \%$ & $-103,2 \%$ & $-65,58 \%$ & $-116,9 \%$ & $-67,87 \%$ & $-142,4 \%$ & $-109,4 \%$ & $-111,1 \%$ & $-132,7 \%$ \\
\hline \multirow{2}{*}{ Não observáveis } & $-0,0650$ & $-0,1294$ & $-0,1165$ & $-0,1071$ & $-0,1598$ & $-0,0804$ & $-0,1124$ & $-0,1220$ & $-0,1098$ & $-0,1228$ \\
\hline & $148,98 \%$ & $197,12 \%$ & $203,25 \%$ & $165,58 \%$ & $216,91 \%$ & $167,87 \%$ & $242,45 \%$ & $209,48 \%$ & $211,19 \%$ & $232,71 \%$ \\
\hline TOT & \begin{tabular}{|l|}
$-0,0436$ \\
\end{tabular} & $-0,0656$ & $-0,0573$ & $-0,0647$ & $-0,0737$ & $-0,0479$ & $-0,0464$ & $-0,0582$ & $-0,0520$ & $-0,0528$ \\
\hline
\end{tabular}

Notas: (a) $\mathrm{RMB}=$ Belém, $\mathrm{RMF}=$ Fortaleza $\mathrm{RMR}=$ Recife, $\mathrm{RMS}=$ Salvador, $\mathrm{RMH}=$ Belo Horizonte, $\mathrm{RRJ}=$ Rio de Janeiro, RSP = São Paulo, RMC = Curitiba, RMPA = Porto Alegre, $\mathrm{DF}=$ Distrito Federal; (b) TOT: Diferencial Total; DOT: Efeito Dotação; DISC: Efeito Discriminação.

Fonte: Elaboração própria a partir dos dados da pesquisa. 
$\mathrm{Na}$ ocupação de técnicos, as características observáveis (DF+DM+DX) atuam para aumentar a diferença de salários entre homes e mulheres nas RM de Belém, Salvador e Porto Alegre, apesar do efeito dotação (DX) ser nulo para Belém e próximo de zero para Salvador e Porto Alegre. Com relação ao efeito discriminação, esse atua de forma mais significativa para aumentar o hiato salarial, corroborando com os resultados encontrados nas demais ocupações, dessa forma, fatores não observáveis potencializam o efeito total da diferença de salários. Portanto, a diferença salarial para esse mercado de trabalho, é reforçada pelo efeito de características observáveis em algumas regiões; isso indica que os níveis de educação e experiência, características que deveriam atuar na diminuição da discriminação, agem para aumentá-la. Por fim, a RM de São Paulo é a que tem o maior efeito total sobre a discriminação e Belém com o menor efeito sobre os trabalhadores do sexo masculino e feminino.

A classe de serviços, grupo com menores níveis educacionais e de experiência, foi a única categoria cujo efeito dotação se mostrou mais expressivo em todas as RMs. Apesar disso, esse efeito não teve força na diminuição das diferenças salariais entre os trabalhadores do sexo masculino e feminino. Por outro lado, as características não observáveis influenciam a discriminação em todas as RMs. A região metropolitana de Belo Horizonte é a que mais discrimina nessa classe, em valores absolutos, e que possui o maior diferencial de salários entre mulheres e homens. Dessa forma, as especificidades entre as regiões, bem como a pouca qualificação nessa categoria seria, possivelmente, o fator determinante das diferenças salariais e não a discriminação.

\subsection{Análise das Diferenças Salariais por Ocupações e RM: Comparação entre as Raças}

O "gap" existente entre os rendimentos de trabalhadores não brancos e brancos, captado pelo diferencial total é, em sua maioria, negativo, excetuando-se as RMs de Belém para ocupação de dirigentes e Fortaleza para as ocupações de dirigentes e técnicos, como pode ser verificado na Tabela 5. Percebe-se que as ocupações que necessitam de mais acumulação de capital humano (dirigentes e profissionais das ciências e das artes) exibem maiores diferenciais de rendimento entre brancos e não brancos. Por outro lado, nas categorias com menores níveis de educação e menos experiência, o mercado de trabalho discrimina menos. Esses resultados corroboram com 
as estatísticas descritivas apresentadas na seção anterior, onde trabalhadores não brancos tem em média menos anos de estudo e, consequentemente, estão presentes nas ocupações que necessitam de menos educação, havendo menor discriminação.

Tabela 5 - Decomposição de Ñopo (2008) por Raça e Regiões Metropolitanas, 2014 Ocupações desagrupadas

\begin{tabular}{|c|c|c|c|c|c|c|c|c|c|c|}
\hline \multirow{2}{*}{ Efeitos } & \multicolumn{10}{|c|}{ Dirigentes } \\
\hline & RMB & RMF & RMR & RMS & RBH & RRJ & RSP & RMC & RMPOA & DF \\
\hline DF & $-0,0124$ & $-0,0006$ & $-0,0025$ & 0,0301 & $-0,0031$ & 0,0280 & $-0,0108$ & 0,0159 & $-0,0005$ & $-0,0004$ \\
\hline Do & 0,0779 & $-0,0644$ & 0,0293 & $-0,0733$ & $-0,0276$ & $-0,0691$ & 0,0176 & $-0,0641$ & 0,0102 & $-0,0694$ \\
\hline DX & 0,0000 & 0,0000 & 0,0009 & 0,0000 & 0,0000 & 0,0000 & 0,0000 & 0,0000 & 0,0000 & 0,0000 \\
\hline DM &, 0156 & 0,0091 & $-0,0335$ & $-0,0099$ & $-0,0139$ & $-0,0155$ & $-0,0318$ & $-0,0140$ & $-0,0460$ & 0,0135 \\
\hline \multirow{2}{*}{ Observáveis } & $-0,0280$ & 0,0085 & $-0,0351$ & 0,0202 & $-0,0170$ & 0,0124 & $-0,0427$ & 0,0019 & $-0,0464$ & 0,0131 \\
\hline & $-56,16 \%$ & $-15,21 \%$ & $604,02 \%$ & $-38,18 \%$ & $38,08 \%$ & $-21,89 \%$ & $170,06 \%$ & $-3,09 \%$ & $128,31 \%$ & $-23,23 \%$ \\
\hline \multirow{2}{*}{ Não observáveis } & 0,0779 & $-0,0644$ & 0,0293 & $-0,0733$ & $-0,0276$ & $-0,0691$ & 0,0176 & $-0,0641$ & 0,0102 & $-0,0694$ \\
\hline & $156,16 \%$ & $115,21 \%$ & $-504,0 \%$ & $138,18 \%$ & $61,92 \%$ & $121,89 \%$ & $-70,06 \%$ & $103,09 \%$ & $-28,31 \%$ & $123,23 \%$ \\
\hline TOT & 0,0499 & $-0,0559$ & $-0,0058$ & $-0,0530$ & $-0,0446$ & $-0,0567$ & $-0,0251$ & $-0,0622$ & $-0,0362$ & $-0,0563$ \\
\hline \multicolumn{11}{|c|}{ Técnicos } \\
\hline DF & $-0,0347$ & $-0,0324$ & $-0,0274$ & 0,0233 & 0,0027 & 0,0063 & 0,0170 & $-0,0075$ & 0,0071 & 0,0028 \\
\hline Do & 0,0406 & 0,0259 & $-0,0370$ & $-0,1123$ & $-0,0268$ & $-0,1153$ & $-0,0255$ & $-0,1164$ & $-0,0021$ & $-0,0353$ \\
\hline DX & 0,0000 & $-0,0006$ & $-0,0014$ & 0,0000 & 0,0000 & $-0,0007$ & $-0,0005$ & 0,0060 & 0,0000 & 0,0000 \\
\hline DM & 0,0017 & 0,0073 & 0,0423 & 0,0444 & 0,0074 & 0,0545 & $-0,0210$ & 0,0609 & $-0,0205$ & 0,0019 \\
\hline \multirow{2}{*}{ Observáveis } & $-0,0330$ & $-0,0256$ & 0,0136 & 0,0676 & 0,0100 & 0,0601 & $-0,0045$ & 0,0594 & $-0,0134$ & 0,0047 \\
\hline & $-435,0 \%$ & $-8339,4 \%$ & $-57,88 \%$ & $-151,5 \%$ & $-59,48 \%$ & $-108,8 \%$ & $15,06 \%$ & $-104,0 \%$ & $86,62 \%$ & $-15,31 \%$ \\
\hline \multirow{2}{*}{ Não observáveis } & 0,0406 & 0,0259 & $-0,0370$ & $-0,1123$ & $-0,0268$ & $-0,1153$ & $-0,0255$ & $-0,1164$ & $-0,0021$ & $-0,0353$ \\
\hline & $535,08 \%$ & $8439,45 \%$ & $157,88 \%$ & $251,58 \%$ & $159,48 \%$ & $208,83 \%$ & $84,94 \%$ & $204,02 \%$ & $13,38 \%$ & $115,31 \%$ \\
\hline$T$ & 0,0076 & 0,0003 & $-0,0234$ & $-0,0446$ & $-0,0168$ & $-0,0552$ & $-0,0300$ & $-0,0571$ & $-0,0155$ & $-0,0306$ \\
\hline \multicolumn{11}{|c|}{ Serviços } \\
\hline D & 144 & $-0,0344$ & $-0,0310$ & $-0,0539$ & $-0,0243$ & $-0,0135$ & $-0,0201$ & $-0,0134$ & $-0,0429$ & $-0,0270$ \\
\hline & 0237 & $-0,0306$ & $-0,0306$ & $-0,0068$ & & 10 & $-0,0110$ & $-0,0103$ & $-0,0136$ & $-0,0086$ \\
\hline 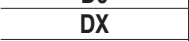 & 027 & $-0,0034$ & $-0,0052$ & $-0,0085$ & $-0,0$ & $-0,0001$ & $-0,0003$ & 0,0017 & 0,0073 & 0,0019 \\
\hline & 237 & 0,0575 & 0,0459 & 0,0564 & & 0,0128 & 0,0209 & 0,0111 & 0,0378 & 0,0208 \\
\hline \multirow{2}{*}{ Observáveis } & 0,0065 & 0,0197 & 0,0098 & $-0,0060$ & 0,00 & $-0,0007$ & 0,0005 & $-0,0006$ & 0,0021 & $-0,0043$ \\
\hline & $-38,06 \%$ & $-181,14 \%$ & $-46,75 \%$ & $46,87 \%$ & -43 & $5,89 \%$ & $-4,53 \%$ & $5,60 \%$ & $-18,19 \%$ & $33,10 \%$ \\
\hline \multirow{2}{*}{ Não observáveis } & $-0,0237$ & $-0,0306$ & $-0,0306$ & $-0,0068$ & $-0,0137$ & $-0,0110$ & $-0,0110$ & $-0,0103$ & $-0,0136$ & $-0,0086$ \\
\hline & $138,06 \%$ & & & & & & & & & $66,90 \%$ \\
\hline TOT & $-0,0172$ & $-0,0109$ & $-0,0209$ & $-0,0127$ & $-0,0095$ & $-0,0117$ & $-0,0105$ & $-0,0109$ & $-0,0115$ & $-0,0129$ \\
\hline \multicolumn{11}{|c|}{ Profissionais Ciências e das Artes } \\
\hline DF & 0314 & $-0,0319$ & $-0,0188$ & $-0,0504$ & $-0,0190$ & 0,0000 & $-0,0161$ & 0,0064 & 0,0139 & 0,0151 \\
\hline $\mathrm{D}$ & $-0,0578$ & $-0,1786$ & $-0,0690$ & & & $-0,0582$ & 0,0024 & $-0,1768$ & $-0,0474$ & $-0,0381$ \\
\hline DX & $-0,0088$ & 0,0000 & 0,0000 & $-0,0161$ & $-0,0016$ & $-0,0015$ & $-0,0012$ & 0,0000 & 0,0000 & $-0,0018$ \\
\hline DM & 0,0457 & 0,1242 & 0,0612 & 0,0347 & 0,042 & $-0,0034$ & $-0,0046$ & 0,1119 & $-0,0052$ & $-0,0032$ \\
\hline \multirow{2}{*}{ Observáveis } & 0,0055 & 0,0923 & 0,0424 & $-0,0317$ & 0,02 & $-0,0050$ & $-0,0218$ & 0,1183 & 0,0086 & 0,0101 \\
\hline & $57 \%$ & $-107,04 \%$ & $-159,7 \%$ & & & $7,85 \%$ & $112,24 \%$ & $-202,3 \%$ & $-22,23 \%$ & $-35,94 \%$ \\
\hline \multirow[b]{2}{*}{ Não observáveis } & $-0,0578$ & $-0,1786$ & $-0,0690$ & $-0,0091$ & $-0,0960$ & $-0,0582$ & 0,0024 & $-0,1768$ & $-0,0474$ & $-0,0381$ \\
\hline & $110,57 \%$ & $207,04 \%$ & $259,70 \%$ & $22,30 \%$ & $129,50 \%$ & $92,15 \%$ & $-12,24 \%$ & $302,38 \%$ & $122,23 \%$ & $135,94 \%$ \\
\hline TOT & $-0,0523$ & $-0,0863$ & $-0,0266$ & $-0,0409$ & $-0,0741$ & $-0,0632$ & $-0,0195$ & $-0,0585$ & $-0,0388$ & $-0,0280$ \\
\hline
\end{tabular}

Notas: (a) $\mathrm{RMB}=$ Belém, $\mathrm{RMF}=$ Fortaleza, $\mathrm{RMR}=$ Recife, $\mathrm{RMS}=$ Salvador, $\mathrm{RMH}=$ Belo Horizonte, $\mathrm{RRJ}=$ Rio de Janeiro, RSP $=$ São Paulo, $\mathrm{RMC}=$ Curitiba, $\mathrm{RMPA}=$ Porto Alegre, $\mathrm{DF}=$ Distrito Federal; (b) TOT: Diferencial Total; DOT: Efeito Dotação; DISC: Efeito Discriminação.

Fonte: Elaboração própria a partir dos dados da pesquisa. 
Com relação à diferença entre brancos e não brancos na RM de Belém, os resultados obtidos para o grupo dos dirigentes podem ter sido causados pela baixa representatividade dos não brancos nesta categoria ocupacional, ou pela singularidade das etnias da Região Norte. Isto posto, esses resultados devem ser um indicativo de que os grupos em comparação não possuem dotações que os façam ter melhores salários. Ainda nessa região, há uma parcela maior do grupo de indígenas que, neste trabalho, não foram analisados de forma separada, podendo ter impactos nos resultados obtidos. Uma possibilidade de melhoria desse resultado seria a comparação entre três grupos raciais: brancos, negros e indígenas; entretanto, para o propósito desta pesquisa, isto não será realizado.

A região metropolitana de Fortaleza na ocupação de profissionais das ciências e das artes $(-0,0862)$ apresenta a maior disparidade salarial entre todas as ocupações. Por outro lado, a RM de Recife $(-0,0058)$ tem a menor diferença salarial inter-racial, observada para os dirigentes. O efeito das características observáveis $(\mathrm{DNB}+\mathrm{DB}+\mathrm{DX})$ agiu como um redutor do diferencial entre os trabalhadores não brancos e brancos. Entretanto, como corrido na análise para gênero, o efeito dotação (DX) é zero ou próximo de zero em todas as ocupações. O efeito discriminação (D0), por outro lado, atuou no sentido de aumentar a disparidade salarial entre esses dois grupos.

Verificando os componentes da diferença salarial, pode-se observar efeitos distintos nas decomposições entre as ocupações. Como esperado, o efeito dotação (DX) para todas as ocupações variou entre nulo ou próximo de zero, excetuando-se a ocupação dos profissionais de serviços, sobre os quais esse efeito agiu no sentido de aumentar o diferencial para as classes aqui analisadas: dirigentes, profissionais das ciências e das artes, dos serviços e técnicos. O efeito discriminação (D0) agiu de forma a aumentar a diferença salarial, excetuando-se as categorias de dirigentes na RM de Belém e nas ocupações de dirigentes e técnicos na região metropolitana de Belém e Fortaleza.

Esses resultados encontrados indicam que o mercado de trabalho nas regiões metropolitanas brasileiras, para as ocupações analisadas neste estudo, comporta-se de forma homogênea quanto a discriminação por raça, corroborando com a literatura para a análise do Brasil com todas as ocupações. 


\section{Considerações Finais}

Este trabalho teve como objetivo mensurar o comportamento do diferencial salarial entre gêneros e entre raças nas regiões metropolitanas, considerando as diferentes categorias ocupacionais, a saber, todas as ocupações, dirigentes, técnicos, profissionais das ciências e das artes e serviços. Além disso, uma das contribuições deste estudo para a literatura reside na aplicação de um novo método de decomposição a dados sobre diferenciais de rendimentos no mercado de trabalho brasileiro, incorporando o índice de custo de vida (ICV), desenvolvido por Azzoni e Almeida (2016) para essas regiões.

Para tanto, este trabalho utilizou o procedimento de Ñopo (2008), método não paramétrico que utiliza técnicas de pareamento para explicar os diferenciais de rendimentos e não requer a estimação da equação de rendimentos para comparação entre grupos diferentes. Porém, para o Brasil, foi feito uma comparação com a decomposição de Oaxaca-Blinder (1973), pois este é um dos métodos mais utilizados na literatura para determinação dos diferenciais de rendimentos entre gêneros e entre raças no mercado de trabalho, objetivando constatar que esta tende a superestimar os efeitos atribuídos às diferenças nos ganhos.

A partir dos pareamentos utilizados no modelo de Nopo para se obter o diferencial de rendimentos entre os grupos analisados, pôde-se observar a existência de diferentes percentuais de indivíduos com características similares pertencentes ao suporte comum. Ao comparar os resultados da decomposição de Ñopo (2008) com Oaxaca-Blinder (1973), verificou-se que existe uma superestimação para todas as categorias no Brasil metropolitano.

Esses resultados demostraram que, ao utilizar o método de Oaxaca, possivelmente, a diferença salarial entre mulheres e homens e não brancos e brancos esteja comprometida, uma vez que, esses diferenciais podem estar relacionados a outras características pessoais, regionais ou voltadas ao mercado de trabalho, tais como, escolaridade, experiência, setor de trabalho, tipos de atividades, horas trabalhadas, dentre outras, já que este método não considera um pareamento dessas variáveis. Além disso, o modelo de Nopo mostrou que para o Brasil metropolitano os resultados seguem a literatura nacional e internacional, tanto para gênero quanto para raça. Como foi efetuado o pareamento entre as variáveis, o efeito dotação foi pratica- 
mente nulo, uma vez que estão sendo comparados indivíduos semelhantes; por outro lado, o efeito discriminação (não observáveis) continua agindo de forma a aumentar as diferenças entre gêneros e raças.

Dentre as ocupações, a categoria dos profissionais das ciências e das artes possui maiores diferenciais de rendimentos entre homens e mulheres. Porém, o efeito discriminatório é sempre superior em todas as ocupações, agindo para aumentar o diferencial de rendimentos, com destaque para as ocupações de serviços, seguido de técnicos, corroborando os resultados encontrados por Gomes e Souza (2016), os quais afirmaram que, apesar da maior absorção do trabalho feminino nos setores de Comércio e Serviços, ainda assim, nesses setores, existe discriminação de rendimentos contra as mulheres, em um menor grau no comércio e maior nos serviços. Analisando as ocupações por raça, o efeito discriminação, em termos absolutos, apresentou-se mais forte para a categoria dos técnicos e profissionais das ciências e das artes, enquanto que a categoria dos dirigentes se apresentou como a de menor efeito discriminação sobre os diferenciais de rendimentos.

Nas ocupações desagregadas, separadas por regiões metropolitanas, observou-se que a ocupação dos profissionais das ciências e das artes é aquela que tem as maiores diferenças salariais nas RMs, com destaque para: Salvador, Belo Horizonte e Curitiba, sendo que o maior efeito total ocorre para a região metropolitana de Salvador. Entre os diferenciais por gêneros, grupo com alto nível educacional, bem como elevada experiência, os resultados indicam que a diferença salarial positiva para os trabalhadores do sexo masculino é presente em todas as RMs, sendo que Fortaleza e Rio de janeiro apresentam, respectivamente, o maior e o menor diferencial total. Em relação aos técnicos, grupo que, teoricamente exige menos anos estudo, este apresenta, em média, maior efeito na discriminação, quando comparado às demais categorias. A classe de serviços foi a única categoria cujo efeito dotação se mostrou mais expressivo em todas as RMs. Apesar disso, esse efeito não teve força na diminuição das diferenças salariais entre os trabalhadores do sexo masculino e feminino. Por outro lado, as características não observáveis influenciam a discriminação em todas as RMs, sendo a região metropolitana de Belo Horizonte aquela que mais discrimina nessa classe, em valores absolutos, e que possui o maior diferencial de salários entre mulheres e homens. 
Para a decomposição dos diferenciais de salários entre raças, por ocupação e por RM, os resultados mostram que as maiores diferenças são encontradas para o grupo de dirigentes e profissionais das ciências e das artes, enquanto as menores para os profissionais dos serviços e técnicos, ou seja, percebe-se que entre as ocupações que necessitam de mais acumulação de capital humano existem maiores diferenciais de rendimento entre brancos e não brancos, sendo que a região metropolitana de Fortaleza na ocupação de profissionais das ciências e das artes apresenta maior disparidade salarial entre todas as ocupações. Por outro lado, a RM de Recife tem a menor diferença salarial inter-racial, observada para os dirigentes.

Os resultados obtidos tanto para gênero quanto para raça, por região metropolitana, validam os observados na análise para o Brasil Metropolitano, no sentido de existir um "gap" salarial a favor dos homens quando se verifica gênero, e favorável aos brancos quando se examina raça. Além disso, pode-se verificar que a discriminação é distinta em cada RM, indicando que o comportamento do mercado de trabalho por RM é diferenciado, corroborando com a análise de Saboia (2014). Ademais, como verificado em Menezes (2013), é necessário examinar as classes de ocupações de forma desagregada, para que se possa conhecer a discriminação dentro das ocupações.

Por fim, a análise sugere que mesmo com a implantação de políticas públicas ativas sobre o mercado de trabalho e acesso à educação como, por exemplo, a lei de $\operatorname{cotas}^{20}$ de acesso à Universidade, e também a redução da taxa de desemprego ocorrida na última década, estas ainda não conseguiram modificar o curso do mercado de trabalho, no sentido de reduzir a discriminação intergênero e inter-racial.

${ }^{20}$ Lei $^{\circ}$ 12.711/2012. Perguntas frequentes sobre a lei de cotas disponível em http://portal.mec.gov.br/ cotas/perguntas-frequentes.html 


\section{Referências}

Azzoni, C. R., ALMEIDA, A. N. 2016. “Custo de vida comparativo das regiões metropolitanas brasileiras: 1996 - 2014”. Estudos Econômicos, 46 (1): 253-276

Barbosa-Filho, F. H. 2014. "Mercado de trabalho no Brasil: passado, presente e futuro". In: Panorama do mercado de trabalho no Brasil/Regis Bonelli, Fernando Veloso (org.). Editora FGV.

Blinder, A. S. 1973. "Wage Discrimination: Reduced Form and Structural Estimates". Journal of Human Resources, 8: 436-455.

Cacciamali, M. C., Tatei, F., Rosalino, J. W. 2009. "Estreitamento dos diferenciais de salários e aumento do grau de discriminação: limitações da mensuração padrão?" Planejamento e políticas públicas. 33: 195-222.

Camargo, J. M. "Evolução recente do mercado de trabalho e suas perspectivas". In: Panorama do mercado de trabalho no Brasil / Regis Bonelli, Fernando Veloso (org.). - Rio de Janeiro: Editora FGV, 2014.

Cambota, J. N. 2005. "Discriminação Salarial por raça e gênero no mercado de trabalho das regiões nordeste e sudeste do Brasil: uma aplicação de simulações contrafactuais e regressão quantílica". 42f. Dissertação (Mestrado). Universidade Federal do Ceará. Programa de Pós Graduação em Economia, CAEN.

Carvalho, A. P., Neri, M. C., Silva, D. B. N. 2006. "Diferenciais de Salários por Raça e Gênero no Brasil: Aplicação dos Procedimentos de Oaxaca e Heckman em Pesquisas Amostrais Complexas". XV Encontro Nacional de Estudos Populacionais, ABEP, Caxambu-MG.

Cavalieri, C. H.; Fernandes, R. 1998. "Diferenciais de salários por gênero e cor: uma comparação entre as regiões brasileiras". Revista de Economia Política, 18 (1): 158-175.

Curi, A.Z., Menezes-Filho, N.A. 2004. "Os Determinantes das Transições Ocupacionais no Mercado de trabalho brasileiro”. XXXII Encontro Nacional da Anpec. João Pessoa, 2004.

Fortin, N.M., T. Lemieux, S. FIRPO. "Decomposition Methods in Economics", O. Ashenfelter and D. Card, eds., Handbook of Economics, 4 (A): 1-102.

El-Haddad, A. 2009. "Labor Market Gender Discrimination under Structural Adjustment: The Case of Egypt". Cairo: Social Research Center, Working Paper 3.

Freisleben, V. S., Bezerra, F. M. 2012. "Ainda existe discriminação salarial contra as mulheres no mercado de trabalho da região sul do brasil? Evidências para os anos de 1998 e 2008". Revista Cadernos de Economia, 16 (30 -31): 51- 65 .

Giuberti, A. N., Menezes-Filho, N. 2005. "Discriminação de rendimentos por gênero: uma comparação entre o Brasil e os Estados Unidos”. Economia Aplicada. 9 (3): 369-383.

Gomes, M. R., Souza, S. C. I. 2016. "Diferenças salariais de gênero no Nordeste do Brasil: uma análise das classes de emprego e setores econômicos". Revista Espacios. 37 (37).

Guimarães, D. B. 2013. "Avaliações de abordagens metodológicas da equação de rendimentos aplicadas em cenários selecionados no mercado de trabalho”. 117f. Tese (Doutorado) - Universidade Federal do Ceará. Programa de Pós Graduação em Economia.

IBGE - Instituto Brasileiro de Geografia e Estatística. "Pesquisa Mensal de Emprego e Salário (PME) dezembro 2015". Disponível em: ftp://ftp.ibge.gov.br. Acesso em 18 de fevereiro de 2016.

Jann, B. 2008. "The Oaxaca-Blinder Decomposition for Linear Regression Models". Stata Journal, 8: 435-479.

Leite, M. P., Souza, S. M. 2010. "Igualdade de gênero e raça no Brasil: uma discussão sobre a política pública de emprego". Dados-Revista de Ciências Sociais, 53 (1): 195-231.

Machado, J. A. F., Mata, J. 2005. "Counterfactual Decomposition of Changes in Wage Distributions Using Quantile Regression". Journal of Applied Econometrics, 20: 445-465. 
Matas, R. S., Machado, A. F. 2006. "Diferencial de rendimentos por cor e sexo no Brasil (1987 - 2001)”. Econômica, 8 (1).

Menezes, F. L. S. 2013. "Decomposição dos diferenciais de rendimentos entre os trabalhadores brasileiros por quantis e categorias ocupacionais". 42f. Dissertação (Mestrado) - Universidade Federal do Ceará, Programa de Pós Graduação em Economia, CAEN.

Menezes-Filho, N. A., Cabanas, P. H. F., Komatsu, B. K. 2014. "Tendências Recentes do Mercado de Trabalho Brasileiro". Insper - Centro de Políticas Públicas (CPP), Policy Paper, 10.

Mincer, J. 1974. "Schooling, Experience and Earning”. Columbia University Press, 1974. 152p.

Mysíková, M. 2012. "Gender Wage Gap in The Czech Republic and Central European Countries”. Prague Economic Papers, 3: 328-345.

Ñopo, H. 2008. "Matching as a tool to decompose wage gaps". The review of economics and statistics, 90 (2): 290-299.

Oaxaca, R. L. 1973. "Male-Female Wage Differentials in Urban Labor Markets”. International Economic Review, 14: 693-709.

Observatório das Metrópoles. 2004. "Identificação dos espaços metropolitanos e construção de tipologias: relatório da atividade, 1. S.1. Projeto Análise das Regiões Metropolitanas do Brasil. Disponível em: <http://www. observatoriodasmetropoles.ufrj.br/produtos/produto_mc_1.pdf $>$. Acesso em 08 de agosto de 2015.

Oliveira, C. 2004. "Crescimento econômico das cidades nordestinas: um enfoque da nova geografia econômica". Revista Econômica do Nordeste, 3.

Organização Iinternacional do Trabalho. 2015. "Perfil do Trabalho Decente no Brasil. Um olhar sobre as unidades da federação". Escritório da OIT no Brasil. - Brasília: OIT, 2012. 416p. Disponível em: < http://www.oitbrasil. org.br/sites/default/files/topic/gender/pub/indicadorestdnovo_880.pdf $>$. Acesso em 08 de agosto de 2015.

Pessoa, S., Ferreira, P.C., Oliveira, L.G. 2007. "Por que o Brasil não Precisa de Política Industrial”. Ensaios Econômicos. EPGE, 644.

Ramos, L.”O desempenho recente do mercado de trabalho brasileiro: tendência, fatos estilizados e padrões espaciais". Brasília: Ipea, (Texto para Discussão, n. 1.255)

Rocha, R. M., Magalhães, A. 2013. "Valoração das Amenidades Urbanas: Uma Estimação a partir dos Diferenciais Salariais e do Custo de Habitação para as Regiões Metropolitanas Brasileiras”. Revista Economia Contemporânea, 17 (1): 69-98.

Saboia, J. 2014. "Evolução recente do mercado de trabalho metropolitano e suas perspectivas". In: Panorama do mercado de trabalho no Brasil / Regis Bonelli, Fernando Veloso (org.), FGV.

Souza, S. C. I., Maia, K., Moura, F. K. I., Gomes, M. R., Silva, R. J. "Diferenças Salariais por Gênero e Cor e o Impacto da Discriminação". Econômica. Revista Brasileira de Estudos Regionais e Urbanos, 9 (1): 32-49.

Souza, M. O., Camara, O. R. A. 2005. "Discriminação e Viés de seletividade: uma análise da Indústria Financeira Brasileira". Revista Brasileira de Economias de Empresas, 5 (1): 7-16.

Wang,Y. 2001. "Melhorando a distribuição de oportunidades. In.: THOMAS, Vinod et al. "A qualidade do crescimento". Tradução Élcio Fernandes, UNESP, cap.3: 51-58. 


\section{Anexo}

\section{Tabela Al - Índice de Custo de Vida por RM}

\begin{tabular}{cccccccccc}
\hline RMB & RMF & RMR & RMS & RBH & RRJ & RSP & RMC & RMPA & DF \\
\hline 0.010 & 0.0191 & 0.0187 & 0.0191 & 0.0218 & 0.0228 & 0.0235 & 0.0214 & 0.0217 & 0.0253 \\
\hline
\end{tabular}

Fonte: Azzoni e Almeida (2016).

Elaboração própria.

1 Apesar da mudança a partir de 2011, do conceito de População em Idade Ativa, os autores usaram o conceito antigo, para ser mais fácil a comparação. A partir de 2011, o IBGE passou a adotar a População em Idade Ativa as pessoas com 15 ou mais anos de idade, não mais a partir de 10 anos de idade ou mais. As pessoas entre 10 e 14 anos têm pouca representatividade na força de trabalho do Brasil.

2 Experiência=idade-anos de educação-6, em que se assume que o indivíduo ingressa no mercado de trabalho após a fase escolar; 6 é a idade em que a pessoa ingressa na escola no Brasil. A anexação dessa variável enfatiza a importância do treinamento no mercado de trabalho. 